\title{
The ins and outs of SARS-CoV-2 variants of concern (VOCs)
}

\author{
Mostafa Salehi-Vaziri ${ }^{1,2,3} \cdot$ Mehdi Fazlalipour $^{1} \cdot$ Seyed Mahmood Seyed Khorrami ${ }^{4} \cdot$ Kayhan Azadmanesh $^{3,5}$. \\ Mohammad Hassan Pouriayevali ${ }^{1,2} \cdot$ Tahmineh Jalali $^{1,2} \cdot$ Zabihollah Shoja $^{5} \cdot$ Ali Maleki $^{1,5}$
}

Received: 4 August 2021 / Accepted: 16 November 2021 / Published online: 28 January 2022

(c) The Author(s), under exclusive licence to Springer-Verlag GmbH Austria, part of Springer Nature 2022

\begin{abstract}
SARS-CoV-2, a newly emerging coronavirus that caused the COVID-19 epidemic, has been spreading quickly throughout the world. Despite immunization and some fairly effective therapeutic regimens, SARS-CoV-2 has been ravaging patients, health workers, and the economy. SARS-CoV-2 mutates and evolves to adapt to its host as a result of extreme selection pressure. As a consequence, new SARS-CoV-2 variants have emerged, some of which are classified as variants of concern (VOC) because they exhibit greater transmissibility, cause more-severe disease, are better able to escape immunity, or cause higher mortality than the original Wuhan strain. Here, we introduce these VOCs and review their characteristics, such as transmissibility, immune escape, mortality risk, and diagnostics.
\end{abstract}

\section{Introduction}

A cluster of etiologically unknown pneumonia was reported to the World Health Organization (WHO) by China's health authority on 31 December 2019. On January 7, a novel coronavirus later named "severe acute respiratory syndrome coronavirus 2" (SARS-CoV-2) was implicated as the etiological agent of the outbreak, and the disease was named "coronavirus disease 2019" (COVID-19) [1-3]. The outbreak became a pandemic in a short time, and as of 27 July, 2021, there have been nearly 194 million confirmed cases of COVID-19 and over 4 ??million?? deaths reported to WHO [1].

SARS-CoV-2 is an enveloped, spherical RNA virus that belongs to the genus Betacoronavirus of the family

Handling Editor: Sheela Ramamoorthy.

Ali Maleki

alimaleki@pasteur.ac.ir; alimaleki.tmu@gmail.com

1 COVID-19 National Reference Laboratory, Pasteur Institute of Iran, 69 Pasteur Ave, 1316943551 Tehran, Iran

2 Department of Arboviruses and Viral Hemorrhagic Fevers (National Reference Laboratory), Pasteur Institute of Iran, Tehran, Iran

3 Research Center for Emerging and Reemerging Infectious Diseases, Pasteur Institute of Iran, Tehran, Iran

4 Department of Virology, Faculty of Medical Sciences, Tarbiat Modares University, Tehran, Iran

5 Department of Molecular Virology, Pasteur Institute of Iran, Tehran, Iran
Coronaviridae, order Nidovirales [2]. The SARS-CoV-2 genome is a $29.9-\mathrm{kb}$ positive-sense single-stranded RNA molecule containing 14 ORFs, which encode four structural and 16 nonstructural proteins (nsp 1-16). The structural proteins include the spike (S) protein, envelope (E) protein, membrane $(\mathrm{M})$ protein, and nucleoprotein $(\mathrm{N})$. The nonstructural proteins are involved in viral RNA replication and gene expression, assembling an RNA synthesis complex in which nsp12 functions as an RNA-dependent RNA polymerase [3]. Unlike other RNA viruses, coronaviruses have RNA proofreading machinery to correct genetic mutations due to the $3{ }^{\prime}-5$ ' exonuclease activity of nsp14 [4]. Nevertheless, it has been estimated that SARS-CoV-2 undergoes $3 \times 10^{-6}$ mutations per nucleotide per replication cycle [5].

SARS-CoV-2-infected individuals may experience a range of clinical manifestations, including asymptomatic infection (testing positive for SARS-CoV-2 in virological assays without COVID-19 symptoms), mild illness (fever, cough, sore throat, malaise, headache, myalgia, nausea/ vomiting, diarrhea, anosmia, and ageusia without dyspnea or abnormality in chest imaging), moderate illness (lower respiratory disease with oxygen saturation $(\mathrm{SpO} 2) \geq 94 \%$ ), severe illness (SpO2 less than 94\%, respiratory frequency up to 30 breaths/min, or lung infiltrates over $50 \%$ ), and critical illness (respiratory dysfunction, septic shock, with or without multiple organ failure) [6].

In addition to humans, several animal species, including cats, dogs, and mink, can become infected naturally with SARS-CoV-2. Although SARS-CoV-2 can be transmitted 
from humans to animals and from animals to animals, the risk of animal-to-human transmission is estimated to be low. Nevertheless, there is a probability of mink-to-human spread on mink farms, as has been reported in several countries, including the Netherlands, Denmark, Poland, and the USA [7].

Both innate immunity and both functional arms of the adaptive immune response are involved in defense against COVID-19. The main focus in the study of immunity against SARS-CoV-2 has been on neutralizing antibodies, but cellular immunity also plays a critical role in defense against SARS-CoV-2 infection [8]. Although escape from cellular immunity in SARS-CoV-2 infection also occurs, the main focus of the current literature has been on humoral immune escape and resistance to neutralization by antibodies, particularly in the vaccinated population. Therefore, we also focus on this area in following section related to the immune response resistance.

Changes in nucleic acid sequence are referred to as "mutations", and viruses that harbor different sets of mutations in their genome are called "variants". From a publichealth perspective and based on WHO classification, there are two important types of SARS-CoV-2 variants: variants of concern (VOCs) and variants of interest (VOIs). SARS$\mathrm{CoV}-2$ variants with altered phenotypic properties, including increased transmissibility or virulence or the ability to evade an immune response induced by natural infection or vaccination or to escape neutralization by monoclonal antibodies are designated as VOCs. Variants that have been detected in several countries and have mutations with phenotypic implications are called VOIs.

\section{Variants of concern (VOCs)}

SARS-CoV-2, like other RNA viruses, undergoes genome modifications as a result of virus replication. Although the viral RNA-dependent RNA polymerase (RdRP) complex has proofreading ability that makes nucleotide substitutions less likely than in other RNA viruses, it should be noted that the proofreading mechanism does not prevent deletions in the viral genome. Furthermore, although coronaviruses have a proofreading apparatus, their genomes are still susceptible to recombination and other copy-choice transcriptional errors [9]. These characteristics, together with the high prevalence of the virus in the human population across broad geographical regions, have led to the emergence of new virus variants that differ from the original virus circulating in China since December 2019 in terms of transmission, pathogenicity, diagnostics, and vaccine effectiveness. With coronaviruses, variants are common; however, a variant becomes a VOC when its variations have clinical or public-health consequences [10].
In addition to VOCs, the CDC has introduced a different classification for the new variants, which includes three groups: VOIs, VOCs, and Variants of High Consequence (VOHCs) [11]. Based on the CDC's classification, a variant will be declared a VOC when it has some properties such as widespread interference with diagnostic test targets, reduced susceptibility to one or more therapeutic classes, decreased neutralization by antibodies elicited during previous infection or vaccination, reduced vaccine-induced protection from severe disease, or increased transmissibility and disease severity [11].

The three global VOCs are B.1.1.7 (Alpha), B.1.351 (Beta), and P.1 (Gamma), which originally emerged in the United Kingdom, South Africa, and Brazil, respectively [12-14]. B.1.617.2 (Delta), a variant of interest first detected in India last year has recently been declared a variant of global concern by WHO, with preliminary research finding that it spreads more rapidly than previous variants. This fourth variant was classified as a global threat on May 10, 2021 (Supplementary Table S1) [15].

Other variants of interest, such as B.1.427/B.1.429 in the United States, have become prevalent and predominant in particular regions and countries and are anticipated to become VOCs in the future [16]. The US CDC has classified the variants B.1.427 and B.1.429 as VOCs, although WHO has not yet classified them as such so far.

\section{B.1.1.7 variant (Alpha)}

In mid-September 2020, the first case was found in London and Kent, United Kingdom, and in December 2020, 1108 cases of infection with this variant had been identified in the UK. As of March 16, 2021, the Alpha variant had become dominant in 21 countries: the United Kingdom, Ireland, Bulgaria, Slovakia, Israel, Luxembourg, Portugal, Denmark, the Netherlands, Norway, Italy, Belgium, France, Austria, Switzerland, Liechtenstein, Germany, Sweden, Spain, Malta, and Poland. In the United States, the Alpha variant first appeared in November 2020, and the number of cases grew from 76 cases in 12 states on January 13 to 7501 cases in all 50 states by March 23 [17].

On Jan 22, 2021, the UK Government's New and Emerging Respiratory Virus Threats Advisory Group (NERVTAG) published that patients infected with the Alpha variant showed no significant difference in their risk of hospitalization or death (risk ratio [RR] 1.00 [95\% CI 0.58-1.73]). However, the next cohort study with additional data showed an RR of 1.65 (1.21-2.25). Additionally, the London School of Hygiene \& Tropical Medicine and Imperial College London reported a relative hazard of death of 1.35 (95\% CI 1.08-1.68) and a case fatality rate of $1.35(1.18-1.56)$ [18]. This strain has a significantly higher 
rate of transmission (R0) and may be higher among children, while older people appear to be less affected [19].

Graham and colleagues found that individuals infected with the Alpha variant had more variation in their symptoms than previous COVID-19 patients and that loss of taste and smell was less common among patients with the Alpha variant, whereas cough, sore throat, myalgia, and fatigue were more frequent [20,21].

Examination of $\mathrm{S}$ gene mutations showed that the mutation N501Y in the receptor-binding domain (RBD) alters the affinity of virus binding to ACE2, that the $\Delta 69-70$ deletion in the spike contributes to evasion of the immune response, and that $\mathrm{P} 681 \mathrm{H}$ affects the furin cleavage site, altering the susceptibility of the spike to furin cleavage and the infectivity of the virus [22]. Mutations such as $\mathrm{N} 501 \mathrm{Y}$ in the receptor-binding domain of the spike protein possibly affect transmissibility, pathogenicity, and vaccine efficacy [22]. A large number of non-synonymous substitutions have been reported for this variant.

A deletion at positions 69 and 70 of the spike protein $(\Delta 69-70)$, which is associated with diagnostic realtime PCR failure (S gene target failure: SGTF), has been reported to be a marker for the Alpha variant, which was given the name VOC 202012/01 by Public Health England (PHE) [23, 24].

On 2 February 2021, Public Health England had detected a number of Alpha VOC-202012/01 genomes with the E484K mutation, which was called Variant of Concern 202102/02 (VOC-202102/02) [25].

$\mathrm{N} 501 \mathrm{Y}$, a change from asparagine $(\mathrm{N})$ to tyrosine $(\mathrm{Y})$ in the RBD, can increase ACE2 binding affinity and lead to the virus becoming more infectious [26]. Position 501 is in the interior of the spike protein and affects the efficacy of neutralization of virus, but there are currently no neutralization data on N501Y available using polyclonal sera from natural infections. The 69-70 deletion has eluded the immune response in some immunocompromised patients and is associated with other changes in the RBD.

Other mutations, including T1001I, A1708D, I2230T, and del3675-3677SGF in the ORF1ab gene, del69-70HV, del144Y, N501Y, A570D, D614G, P681H, T761I, S982A, and $\mathrm{D} 1118 \mathrm{H}$ in the S gene, Q27stop, R52I, and Y73C in ORF8, and D3L and S235F in the $\mathrm{N}$ gene have been reported, but their effect is not known (Fig. 1, Tables 1,2) [27].

The ChAdOx $1 \mathrm{nCoV}-19$ vaccine (developed by the University of Oxford and AstraZeneca) showed approximately

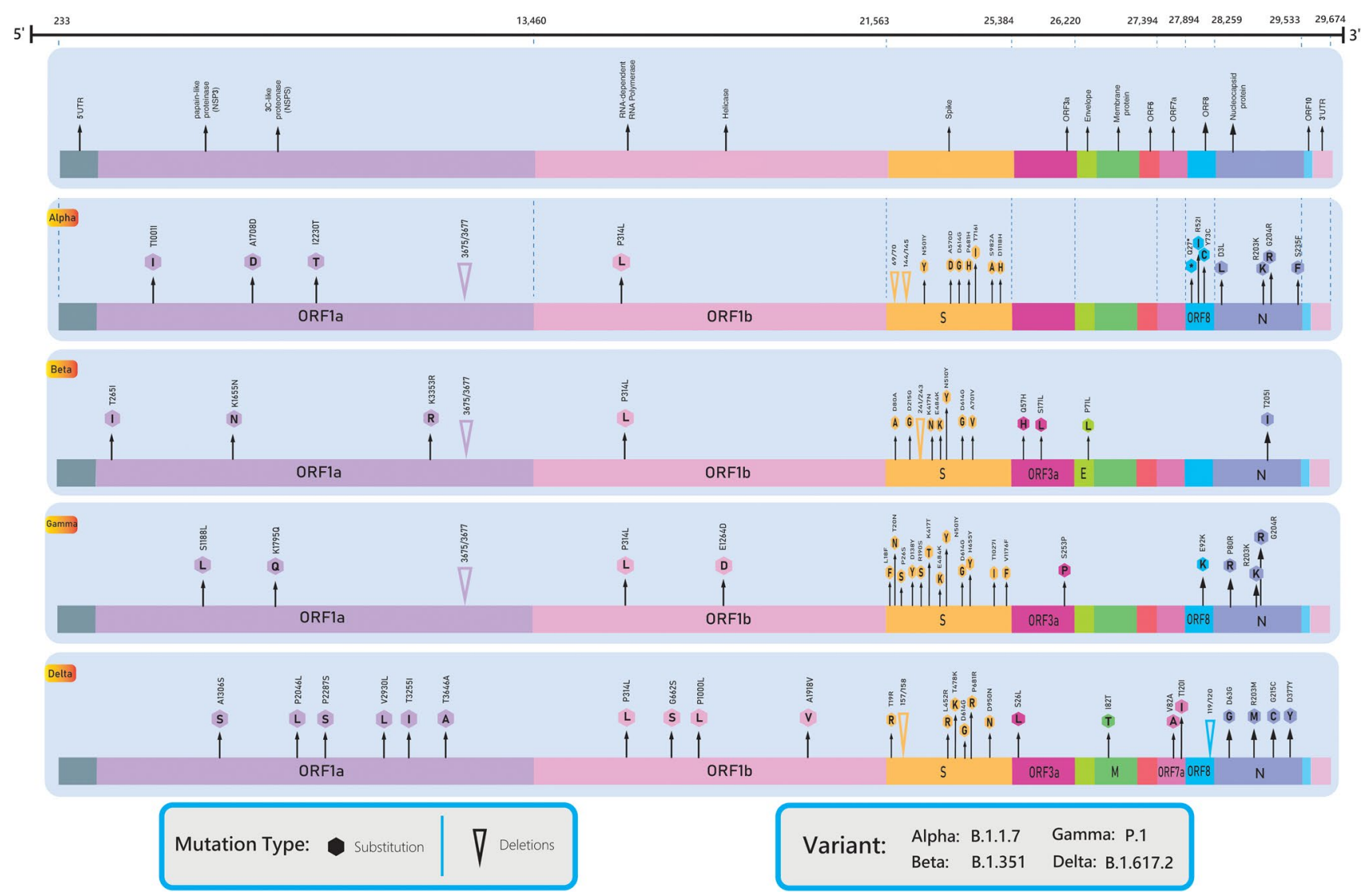

Fig. 1 Schematic view of mutations in four VOCs. The start and end positions of the mutated genes are indicated. 
Table 1 Full list of nomenclature, origin, and mutations in the spike gene of VOCs/VOIs

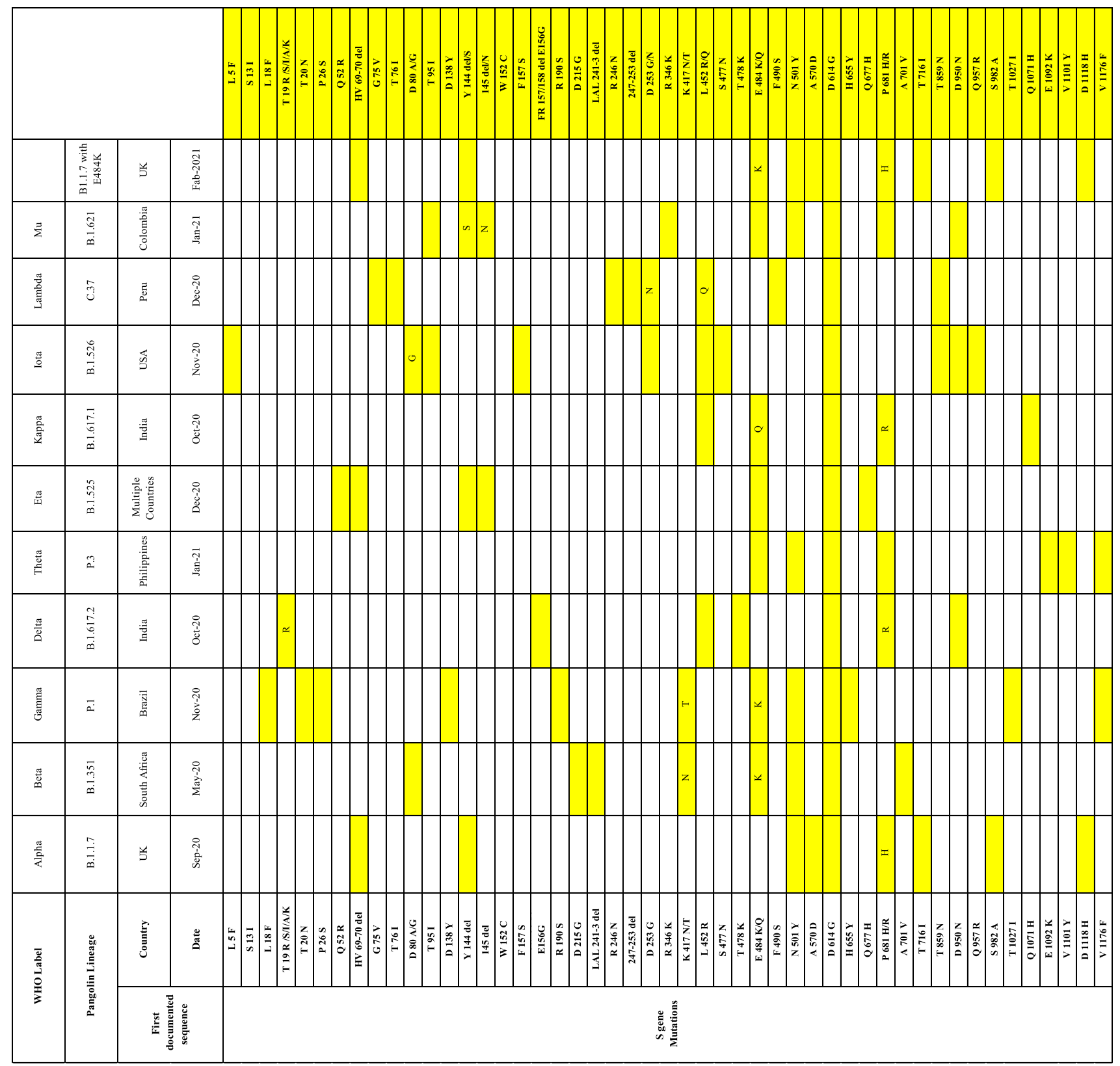

The symbols * and del indicate a stop mutation and a deletion, respectively $[127,128]$

$75 \%$ efficacy against the Alpha variant, compared with $84 \%$ against other lineages [20].

The ORF8 protein is an immunoglobulin-like protein that modulates pathogenesis, mediates degradation of major histocompatibility complex I (MHC-I), and suppresses the type I interferon (IFN)-mediated antiviral response. Genetic sequencing of VOC-202012/01 has shown the presence of a Q27stop mutation that inactivates the ORF8 protein, and this mutation is associated with symptoms and disease outcome $[28,29]$.

\section{B.1.351 variant (Beta)}

In early October 2020, the Beta variant emerged in Nelson Mandela Bay (a metropolitan area of the Eastern Cape province of South Africa). The new variant, named 501Y. V2, is also known as the B.1.351 lineage, or $20 \mathrm{H} / 501 \mathrm{Y}$. V2 Next strain clade. By December 2020, it had spread to Botswana, France, Scotland, South Korea, Sweden, Switzerland, and the UK [30]. 


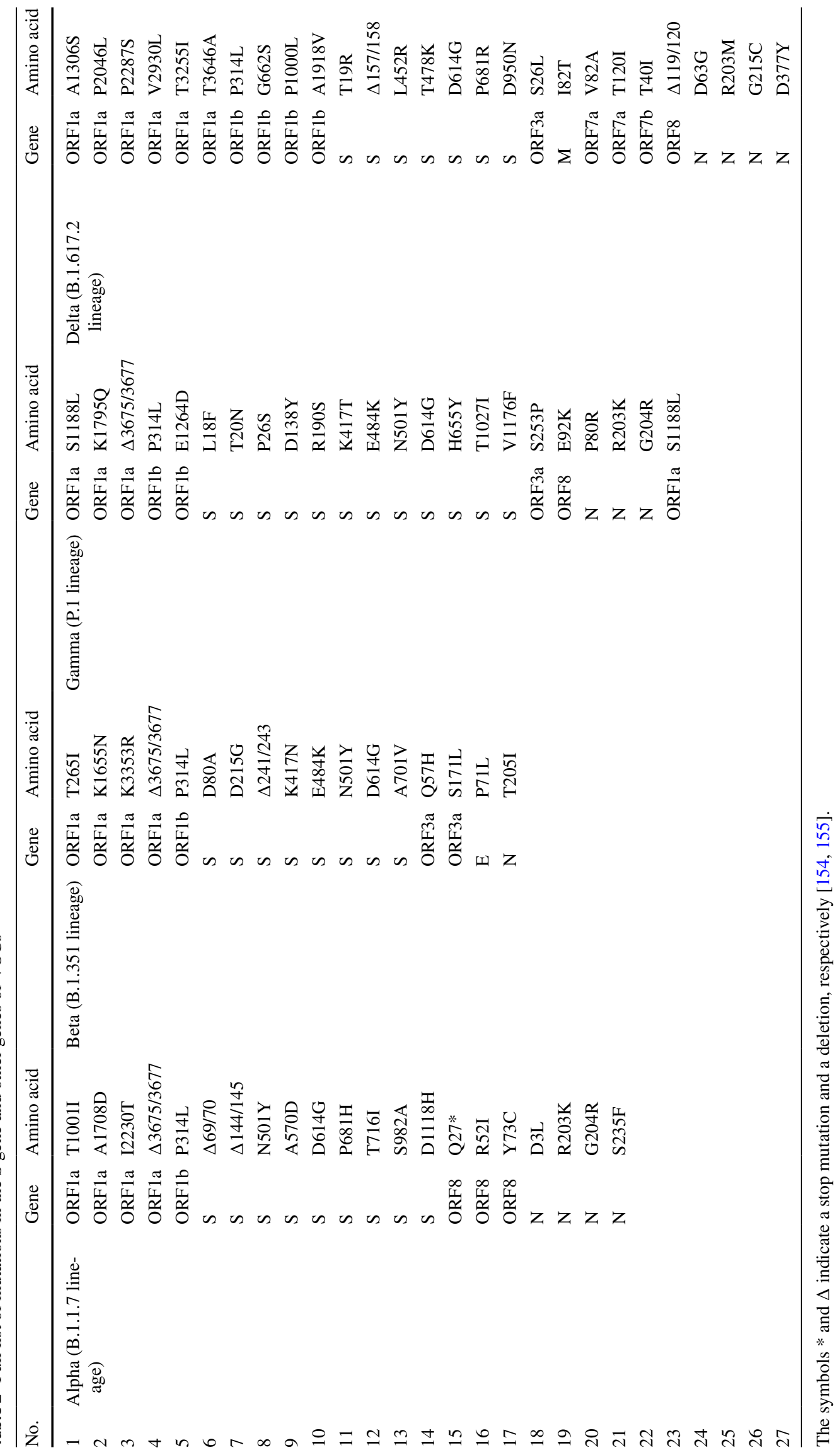


The Beta variant is $50 \%$ more transmissible than the variants that were circulating previously in South Africa, and this resulted in a change in disease severity. Beta variant mutations did not impact the sensitivity of a real-time reverse transcription polymerase chain reaction (RT-PCR) assay targeting the RdRp, Nsp2, E, and N genes [31].

The potential for reinfection with the Beta variant is relatively high because mutations in the Beta variant allow escape from neutralizing antibodies in COVID-19 convalescent plasma [32].

The Beta variant contains nine spike mutations: L18F, D80A, D614G, 242-244del, and R246I in the ??N-terminal domain?? (NTD), K417N, E484K, and N501Y in the RBD, and A701V near the S2 subunit furin cleavage site (Fig. 1, Table 2) [33].

Three of the mutations in the spike region, $\mathrm{K} 417 \mathrm{~N}$, E484K, and N501Y, are more important than the other five. All three are in the RBD and help the virus to attach more easily to human cells and increase the binding affinity for the ACE2 receptor [34].

\section{P.1 variant (Gamma)}

Lineage P.1, also known as 20J/501Y.V3, Variant of Concern 202101/02 (VOC-202101/02), or the Brazilian variant, was first detected on 6 January 2021 by the National Institute of Infectious Diseases (NIID), Japan, in people who had arrived in Tokyo having visited Amazonas, Brazil. It caused widespread infection in the city of Manaus [35]. The Gamma variant caused higher viral loads and showed 1.4-2.2 times higher transmissibility than earlier strains, especially in young patients (no gender differential) [36].

The Brazil-United Kingdom CADDE Centre on 12 January 2021 confirmed the presence of the Gamma variant in Manaus, Amazonas State [35]. Two distinct sub-variants of the Gamma variant, 28-AM-1 and 28-AM-2, carry the K417T, E484K, N501Y mutations, and both originated in Brazil [37].

The Gamma variant contains 10 mutations in the spike (L18F, T20N, P26S, D138Y, R190S, K417T, E484K, N501Y, H655Y, and T1027I) in addition to D614G. K417T, $\mathrm{E} 484 \mathrm{~K}$, and N501Y are in the RBD; L18F, T20N, P26S, D138Y, and R190S are in the NTD; and H655Y is near the furin cleavage site (Fig. 1, Table 2) [38, 39]. The K417T and N501Y mutations are present in both the Alpha and Beta variants and help the virus to attach tightly to human cells. E484K can help the virus evade antibodies. A deletion in the orf1b protein (del11288-11296 [3675-3677 SGF]) has been reported [37].

The Gamma variant is different from the other Brazilian lineage P.2 ('B.1.1.28.2' or 'VUI-202101/01'). P.2 only has the E484K mutation in the RBD but neither the N501Y nor the K417T mutation [40].
The novel P.2 lineage was first detected by genome sequencing in October 2020, and during October and November 2020, the E484K mutation was found in all P.2 samples [41]. The P.2-specific mutations are E484K in the S gene, A119S in the N gene, 5'UTR C100U, and L3468V and synC11824U in the ORF1ab gene. Other mutations include 3'UTR C29754U, F120F (synC28253U) in ORF8, M234I in the $\mathrm{N}$ gene, and L3930F and synA12964G in ORF1ab [14, 42].

\section{B.1.617.2 variant (Delta)}

On May 10, 2021, WHO declared the B.1.617 lineage, originally identified in India, the fourth global VOC. This lineage has three sublineages: B.1.617.1, B.1.617.2, and B.1.617.3. There are two signature mutations for the Delta variant in the spike protein, at position 452 in the RBD region and position 681 in the furin cleavage site between S1 and S2, together with the primary D614G mutation. The Delta variant is an exception in the B.1.617 lineage and does not have a substitution at residue 484 (Fig. 1, Table 2) [43, 44]. On June 1, 2021, WHO reported that only the B.1.617.2 sublineage, which was designated the Delta variant, remained a VOC, and sublineage B.1.617.1 was designated the Kappa variant and was classified as a VOI. B.1.617.3 was neither labeled nor reclassified [45].

In comparison to the first wave, other reports indicate that case numbers grew more quickly during the most recent surge when Alpha and Delta variants were circulating (February 11, 2021). Preliminary data and estimates revealed very high test positivity rates (TPRs) and rising case fatality rates (CFRs) in the second surge of COVID19, with Alpha and Delta variants circulating in India [46]. The Delta variant affects serological neutralization and transmissibility, as explained below.

There is a Delta plus variant, which has an additional K417N mutation that allows the virus to better attack lung cells and potentially escape vaccine protection. The Delta plus variant is rapidly spreading in India, the UK, and other countries [47].

\section{Features of VOCs}

The emergence of a VOC indicates that increased spread or pathogenicity of the virus and increased mortality due to COVID-19 must be seriously considered. Mutations accumulate in the viral genome as a result of free circulation of SARS-CoV-2 in communities, which could influence viral transmission, mortality, detection, and immune escape [48]. 


\section{Transmissibility}

The accumulation of silent mutations in the SARS-CoV-2 genome provided a selective advantage in which the Alpha variant rapidly replaced common non-VOCs during autumn 2020 in the UK. Remarkably, as of 27 July 2021, this variant has been reported in 182 countries (Fig. 2) [1, 48-50].

Before the spread of the Delta variant in the UK, SGTF data showed that the Alpha variant, due to increased viral loads, had higher transmissibility than non-VOC lineages in all regions of England and that it was the dominant strain $[48,51]$.

Using multiple models, the Alpha variant in the UK was found to have a higher reproduction number, $\mathrm{R}$, than other strains. Similar increases were reported in Switzerland, Denmark, and the United States [48, 52]. The transmissibility of the Alpha variant has been estimated in various modeling studies. Rates of $68 \%, 75 \%, 56 \%, 40 \%$, and $36 \%$ were reported by Vöhringer et al., Leung et al., Davies et al., Tuite et al., and a study from Denmark, respectively [49, $53,54]$. Davies et al. suggested a relationship between the Alpha variant and more-severe illness compared to previous circulating SARS-CoV-2 variants [54]. After adjustment for confounding factors, Frampton and colleagues found that patients with Alpha and non-Alpha infections showed similar disease severity and clinical outcomes [51]. Some researchers have suggested that the increased transmissibility of the variant is related to increased stability in the environment. However, Schuit and colleagues reported that the stability of the Alpha variant in aerosols is similar to that of the earlier isolates, and therefore, the increased transmissibility of the Alpha variant is not associated with increased virus survival in the environment [55]. Spike mutations, including N501Y, $\mathrm{P} 681 \mathrm{H}$, and 69-70del, are key factors in the increased transmissibility of the B.1.1.7 variant. N501Y, which also is present in the Beta and Gamma variants, increases the affinity of the RBD for ACE2. Experimental studies have shown that N501Y increases the rate of virus replication in both cell culture (human upper airway cells) and animal models (the upper respiratory tracts of hamsters) [56]. The P681H mutation, which is close to the $\mathrm{S} 1 / \mathrm{S} 2$ furin cleavage site, increases transmissibility by increasing the efficiency of $\mathrm{S} 1$ / S2 cleavage in human airway epithelial cells [57, 58].

The rapid transmission observed with the Gamma variant results in a higher estimated $\mathrm{R}$ value for this lineage than for other common circulating lineages (non-VOCs), and this is associated with higher viral loads [59]. In a comparison of Gamma variant infections with non-Gamma infections, Naveca et al. showed that Gamma variant infections were significantly associated with lower $\mathrm{Ct}$ values, $\sim 10$-fold

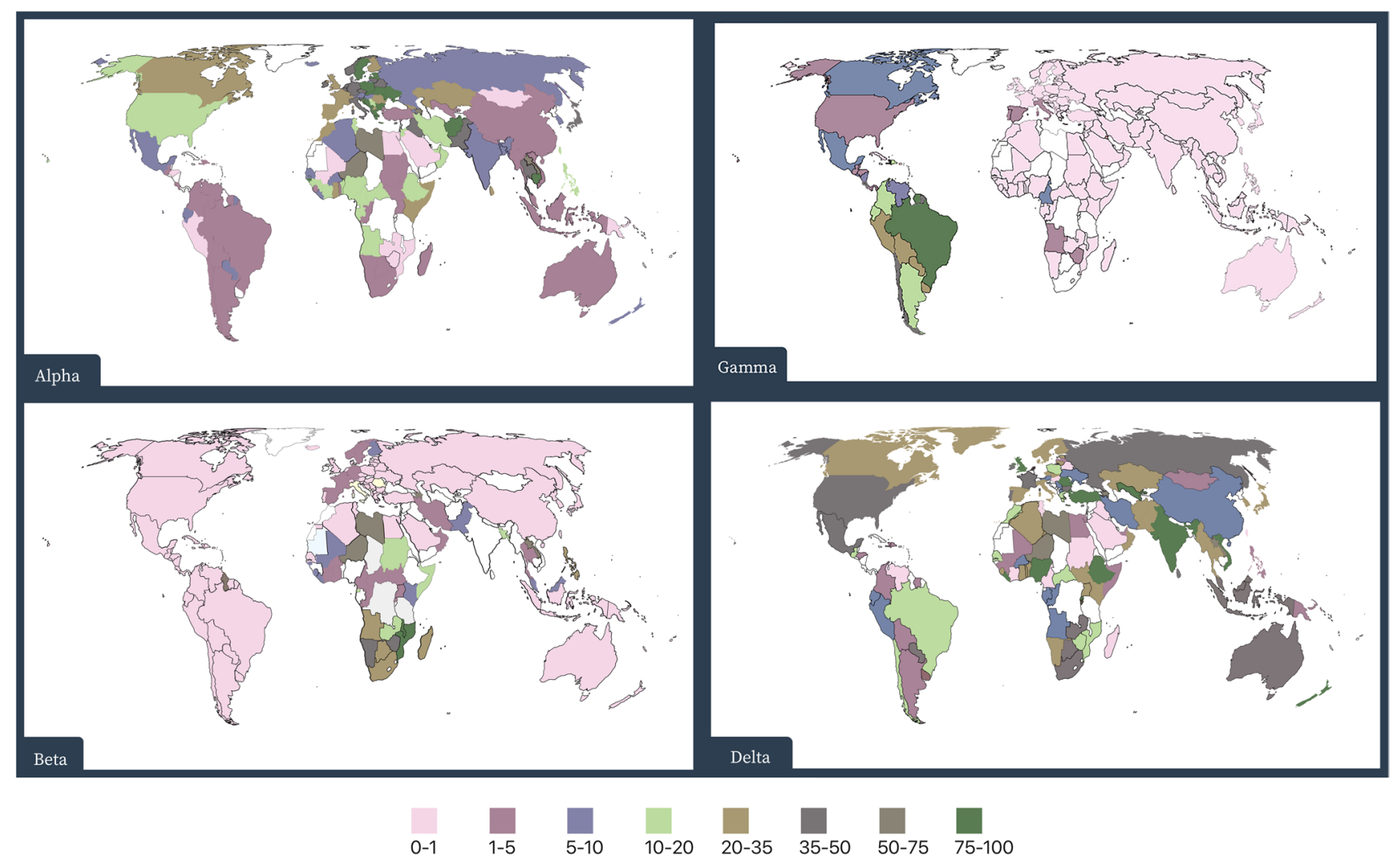

Fig. 2 The global prevalence of the VOCs Alpha, Beta, Gamma, and Delta. The colors indicate \% of prevalence as shown below the figure 
higher viral loads, and equal levels of infectivity for individuals $>18$ years old [60]. Phylodynamic modeling revealed that the Gamma variant could be 2.2-2.5 times more transmissible than the circulating parental lineage, with a probability of reinfection of $6.4 \%$ (CI 5.7-7.1\%) and a $25-61 \%$ higher probability of evading protective immunity. By 27 July 2021, this variant had been reported in 81 countries (Fig. 2) [1, 50, 59, 61, 62].

Preliminary results suggest that the Beta variant, with several mutations in the RBD site of the $\mathrm{S}$ gene (including E484K and N501Y), is probably 50\% more transmissible and capable of immune escape than a co-circulating virus in South Africa. As of 27 July 2021, 131 countries have reported detection of this variant (Fig. 2) [1, 49-51]. Increased transmissibility and immune escape give the 501Y.V2 variant a selective advantage to outcompete other circulating SARS-CoV-2 variants by both rapid expansion and possible reinfection. Substitutions in the RBD of the spike protein (E484K, K417N, and N501Y) in the $501 \mathrm{Y}$. $\mathrm{V} 2$ variant are associated with enhanced binding affinity to human ACE2, which may increase viral transmissibility. As a result of the selective advantage of 501Y.V2, the other circulating lineages in South Africa are rapidly being replaced by this variant [30]. In addition to N501Y, the Gamma and Beta variants have mutations that enhance transmissibility, such as E484K. Similar to N501Y, E484K increases binding affinity to the ACE-2 receptor [63].

The Delta variant quickly became the dominant strain of SARS-CoV-2 in India during the first half of 2021. As of 27 July, 2021, the Delta variant has been reported in 132 countries (Fig. 2) [1]. The spike protein of the Delta variant contains three key mutations: L452R, E484Q, and P681R. These mutations can result in resistance to neutralizing monoclonal antibodies, favor antibody escape, and increase transmissibility by increasing the viral load, respectively [64]. It has been estimated recently that the Delta variant is $41 \%$ more transmissible than the Alpha variant. In a previous report, this value was overestimated (60\% and 50\%) [65]. In addition, the Delta variant carries a higher risk of hospitalization than the Alpha variant.

According to the COVID-19 Weekly Epidemiological Update, the reproduction number relative to non-VOCs was estimated to be 43-93\% (95\% CI 38-130\%), 36\% (95\% CI $32-40 \%)$, and $11 \%$ (95\% CI 7-16\%) for the Alpha variant [66]. The Scientific Advisory Group for Emergencies (SAGE) estimated the R value to be $40-80 \%$ higher for the Delta variant than for the Alpha variant, using multiple modeling [65].

The B.1.427 and B.1.429 (West Coast) variants were first reported in the US state of California, with a similar $20 \%$ increased transmissibility compared to circulating nonB.1.427/B.1.429 lineages. The increased transmissibility may be due to a twofold higher viral load, detected in both infected patients and in in vitro experiments. There are no data about the transmissibility of the B.1.525 (UK and Nigeria) and B.1.1.207 (Nigeria) variants [30, 67, 68].

Pereira reported that SARS-CoV-2 variants combining spike mutations with a lack of ORF8 may be associated with a prolonged infection period, increased virus transmissibility, and less-severe disease [28]. There have been several studies suggesting that the ORF8 protein is involved in immune evasion. There have also been several studies showing that the E484K mutation may be linked to resistance to neutralization by antibodies [30].

The spike protein of B.1.617 contains L452R and E484Q mutations in the $R B D$ region and a $P 681 R$ mutation in the polybasic cleavage site $[69,70]$, which may accelerate the spread of the B.1.617 lineage worldwide. The mutation in the furin cleavage site (P681R) can enhance transmissibility due to an increased rate of membrane fusion and viral entry [43].

Based on epidemiological and modeling data, the Delta variant seems to have a transmission advantage over previously circulating variants $[69,71]$.

\section{Immune escape}

As the infection spreads and the number of immune people grows, the virus gains the ability to evade naturally induced immunity, having a chance to reinfect people [72]. Monitoring of escape mutations should be considered a public health priority. At first, sequencing can be used, but once a variant is recognized as being "of concern", a PCR-based assay or other screening method should be immediately designed, validated, and made accessible globally for efficient realtime monitoring of the variant's distribution [72].

Past serological studies have shown that a typical individual is infected once every 2-4 years with one of the four common cold coronaviruses - HCoV-NL63, HCoV-229E, $\mathrm{HCoV}-\mathrm{OC} 43$, or HCoV-HKU1. This indicates that while reinfection occurs at a low rate, immunity against common cold coronaviruses is not highly durable $[73,74]$.

Deletions in the SARS-CoV-2 spike protein frequently occur in so-called recurrent deletion regions (RDRs), which affect epitopes for antibodies. Ninety percent of RDRs are in one of four discrete sites within the NTD, numbered 1 to 4 from the $5^{\prime}$ to the 3 ' end of the $\mathrm{S}$ gene. Some SARSCoV-2 variants are RDR variants, including mink cluster 5 $\Delta 69-70$, Alpha variant $\Delta 69-70, \Delta 144 / 145$, and Beta variant $\Delta 242-244$. These RDRs confer resistance to neutralizing antibodies [75].

Regarding the D614G variant, in contrast to previous studies with convalescent sera that showed slightly increased neutralization of the D614G variant versus wild-type following natural infection [76], Garcia-Beltran et al. demonstrated that, in individuals who were administered two 
doses of either BNT162b2 or mRNA-1273 vaccines, D614G pseudovirus neutralization was comparable to that of the WT form, with a 1.2-fold decrease for both two-dose vaccines [77]. This discrepancy might be due to the fact that most of the convalescent patients in previous studies were probably infected with the globally dominant D614G variant at that time, while the vaccines contain the wild-type spike sequence. A 1.4- to 2-fold mean reduction in neutralization titer for the B.1.429 variant was also observed in individuals who received two full doses of either a BNT162b2 or an mRNA-1273 vaccine [77].

A recent study revealed that the Alpha variant remains sensitive to neutralization, albeit at moderately reduced levels ( twofold), by serum samples from convalescent individuals and recipients of an mRNA-1273 vaccine (Moderna) and a protein nanoparticle NVXCoV2373 vaccine (Novavax) [78]. These results are in line with others indicating the comparable neutralization capacity of serum panels obtained from convalescent patients and vaccinated individuals against the Alpha variant $[77,79,80]$. Taken together, these recent data revealed that pre-existing immunity against the wild-type spike protein of SARS-CoV-2, either through natural infection or vaccination, provides adequate protection against the Alpha, B.1.429, and B.1.1.298 variants.

Hoffmann et al. showed that soluble ACE2 (sACE2), membrane fusion inhibitors, and TMPRSS2 inhibitors are effective against SARS-CoV-2 and its important variants of concern, particularly the Alpha, Beta, and Gamma variants [81]. However, in the case of antibody therapy, broad cross-neutralization was not always observed. While all of the antibodies evaluated, including casirivimab, imdevimab, and bamlanivimab, inhibited entry and blocked wild-type SARS-CoV-2 infection, only imdevimab showed the same level of inhibition of cell entry driven by the $S$ proteins of the Beta and Gamma variants. In fact, the Beta and Gamma variants showed partial and complete resistance to casirivimab and bamlanivimab, respectively. However, a cocktail of monoclonal antibodies called REGN-COV-2, consisting of casirivimab and imdevimab, efficiently blocked all of the variants tested [81]. On the other hand, sera from convalescent patients and individuals who received a BNT162b2 vaccine showed full protection against wild-type SARS-CoV-2 and slightly less protection against the Alpha variant. Thus, the BNT162b2 vaccine may provide less-reliable protection against infection by the Beta and Gamma variants [81].

Interestingly, Edara et al. reported that despite a few-fold reduction, most infected individuals still had binding and neutralizing antibodies against the Beta variant 8 months after infection. Furthermore, all Moderna mRNA-1273-vaccinated individuals produced neutralizing antibodies against the Beta variant [82]. In contrast, $36.7 \%$ and $42.9 \%$ of individuals who received two doses of BNT162b2 and mRNA1273 , respectively, had no detectable neutralization against the Beta variant. A lack of neutralization of the Beta variant was more likely when only one dose of the mRNA vaccine had been administered [77]. Therefore, a single dose of the current mRNA vaccines might be insufficient to elicit a cross-neutralizing antibody response in previously uninfected individuals.

In another study, in comparison to the Victoria isolate, a Wuhan-related isolate, neutralization titers against the Beta variant were 13.3-fold lower in early convalescent samples. However, when sera from patients infected with the Alpha variant were tested, there was a 3.1-fold difference in neutralization titer between the Victoria isolate and the Beta variant [83]. The neutralization titers of sera from individuals vaccinated with either the Pfizer-BioNTech BNT162b2 or the AstraZeneca/Oxford AZD1222 vaccine were also tested, and the results showed a 7.6- and 9-fold lower geometric mean titer, respectively, for the Beta variant than for the Victoria isolate, [83]. Two of two monoclonal antibody (MAbs) cocktails, one containing MAbs REGN10933 and REGN10987, and one containing MAbs AZD1061 and AZD8895, from Regeneron and AstraZeneca, respectively, were tested against the Beta variant, and it was found that the mutations in the Beta variant had no impact on neutralization by REGN10987, but they negatively impacted neutralization by REGN10933 (773-fold). In contrast, no difference was observed with AZD1061 and AZD8895 [83]. The AZD7442 cocktail, which targets the RBD region, is a combination of two long-acting antibodies (LAABs) generated from $B$ cells from convalescent patients: tixagevimab (AZD8895) and cilgavimab (AZD1061) [84]. Consistent with these data, several other studies have shown a reduction in cross-neutralization of the Beta variant by convalescent and vaccinated sera [77, 80, 85, 86].

A neutralization test using the B.1.427/B.1.429 variant revealed a 4.0- to 6.7-fold reduction in neutralizing titers in sera obtained from convalescent patients in comparison to wild-type pseudoviruses, while a 2.0-fold reduction was observed in mRNA vaccine recipients [16]. This is inconsistent with other studies that showed a reduction in the neutralization titer against the B.1.427/B.1.429 variant [87-89]. In the receptor-binding motif (RBM) of the spike protein, the B.1.427/B.1.429 (CAL.20C) and CAL.20A variants have an L452R substitution. According to one study, $36 \%$ of people who tested positive for SARS-CoV-2 after one or two doses of mRNA vaccine were positive for the L452R mutation, suggesting infection by the B.1.427 or B.1.429 variant [90]. Although vaccination resulted in better protection against the B.1.427 and B.1.429 variants than did natural infection, neither vaccination nor natural infection could confer complete protection against these variants. Presumably, due to the rapid changes occurring in the SARS-CoV-2 spike protein, this protection will be too weak to be protective in the future. 
Regarding ACE2 mimics, the B.1.427 and B.1.429 variants showed moderate resistance to peptide-based inhibitors such as LCB1, and since the L452R mutation is located near the ACE2-LCB1 interface, it might affect the binding affinity of LCB1 [87, 91]. In addition, due to an S13I mutation in the signal peptide cleavage site that causes a significant structural rearrangement of the NTD antigenic supersite, a complete loss of B.1.427/B.1.429 neutralization was observed with a panel of mAbs targeting the NTD [87].

Another investigation showed that despite the B.1.617.1 variant being 6.8 -fold more resistant to neutralization by sera from Moderna- and Pfizer-vaccinated subjects, the B.1.617.1 variant was neutralized by the majority of sera from convalescent patients and all sera from vaccinated individuals [92]. Despite in vitro data showing only a small decrease in neutralization against B.1.617 with the Covaxin vaccine, another study demonstrated vaccine breakthrough in healthcare workers who were fully vaccinated with the ChAdOx-1 vaccine [69, 93].

Regarding vaccine effectiveness (VE) of available vaccines against VOCs, NVX-CoV2373 has shown 86\%, and $60 \%$ efficacy against Alpha and Beta, respectively [94]. The VE of AZD1222 was 70\% against Alpha [95]. The VE after two doses of BNT162b2 mRNA vaccine was estimated to be $89 \%$ against Alpha [96], $86 \%$ against severe infection with Beta [97], 84\% against Beta and Gamma [96], and $87 \%$ against Delta [96]. However, the VE after two doses of mRNA-1273 mRNA vaccine was $92 \%$ and $96.4 \%$ against Alpha [96] and Beta [98], respectively. Another study estimated the VE of full vaccination with the BNT162b2 mRNA vaccine to be around $84.4 \%$, for Alpha and $64.6 \%$ for Delta in Norway [99]. Another study showed the VE of the GamCOVID-Vac (Sputnik V) vaccine to be $78.6 \%$ in elderly people in Argentina for preventing confirmed infections and $87.6 \%$ and $84.8 \%$ for reduction in hospitalizations and deaths, respectively [100].

A series of studies demonstrated that the monoclonal antibodies LY15 CoV555, CB6, REGN10989, REGN10933, and REGN10987 provided a high potency of neutralization against the Alpha variant $\left(\mathrm{IC}_{50}, 0.0001-0.0401 \mu \mathrm{g} / \mathrm{mL}\right)$ but LY-CoV555, CB6, REGN10989, and REGN10933 could not neutralize the Beta variant $\left(\mathrm{IC}_{50}>10 \mu \mathrm{g} / \mathrm{mL}\right)[85,101,102]$. In a study measuring levels of $\operatorname{IgA}$ and $\mathrm{IgG}$ in vaccinated and convalescent saliva samples, convalescent individuals had significantly higher levels of $\operatorname{IgA}$ than vaccinated individuals $(P=0.03)$. Conversely, the $\mathrm{IgG}$ response in the saliva of vaccinated individuals was significantly higher than in saliva from convalescent individuals $(P<0.0001)$ [103].

Once selective pressure is exerted in the context of drug treatment, any drug resistance becomes more evident. Several lines of evidence strongly support the idea that cocktail therapy may be a powerful tool for controlling SARS-CoV-2 mutational escape, particularly when two antibodies bind to distinct and non-overlapping regions of the viral target, such as the RBD, making it unlikely that simultaneous mutations at two different genetic sites will allow viral escape. As a consequence, a therapeutic antibody cocktail may not only treat the disease but also protect against the development of resistance to antibody treatment [102].

L452R and E484Q are mutations in the receptor-binding domain of the spike, which not only binds ACE2 but also serves as a target for neutralizing antibodies. Pseudotyped viruses containing spike proteins of the B1.617.1 sublineage with three signature mutations (L452R, E484Q, and P681R) exhibited moderately decreased sensitivity to antibodies elicited by BNT162b2 mRNA vaccine, comparable to the loss of sensitivity conferred by L452R or E484Q alone [69]. In India, several people who were vaccinated with the Covishield vaccine were infected with the B.1.617 variant. Neutralizing antibodies elicited by natural infection or as a result of vaccination were found to be less effective against the B.1.617 variant $[69,104]$.

The N501Y and E484K mutations, which have been reported recently in VOCs, are located within the RBD. The N501Y mutation, which is present in nearly all of the major circulating VOCs (i.e., the Alpha, Beta, and Gamma variants), has no adverse effect on the neutralizing ability of sera from either naturally infected or mRNA-1273-vaccinated individuals $[57,82,105,106]$. In contrast, the E484K substitution, which is present in the Beta and Gamma variants, is associated with resistance to convalescent sera [86, 106-108]. Reinfection with SARS-CoV-2 has also been correlated with the E484K mutation [109-111], which can help the virus to evade polyclonal antibody responses [112]. Some research has also shown the K417N mutation to play a role in immune escape, especially in evading neutralization by a class of VH3-53/66 antibodies (Table 3) [86].

$\mathrm{N} 439 \mathrm{~K}$ is a mutation that can help the virus to evade antibody-mediated immunity while maintaining fitness in comparison to WT. The N439K RBD retains high-affinity interactions with the hACE2 receptor, and viruses containing the $\mathrm{N} 439 \mathrm{~K}$ mutation replicate efficiently in cultured cells. Furthermore, no difference in disease severity has been associated with this mutation. Evasion of antibodymediated immunity was assessed by testing the recognition of N439K RBD by mAbs and polyclonal sera from 442 convalescent patients [113].

The second arm of the immune response is cellular immunity. T cell epitope substitutions may impair cytotoxic $\mathrm{T}$ lymphocyte or $\mathrm{T}$ helper recognition, resulting in delayed elimination of infected cells or suboptimal B cell and antibody response assistance. T cell epitopes, unlike neutralizing antibody epitopes, are found in the entirety of the spike protein. It is not yet clear how mutations affect $\mathrm{T}$ cell responses or lead to $\mathrm{T}$ cell escape variants. However, the polyclonal response of $\mathrm{T}$ cells targeting several 
Table 3 The signature mutations of VOCs and their functional characteristics

\begin{tabular}{|c|c|c|c|}
\hline Signature mutation & Region & Function & Ref. \\
\hline HV69/70del & NTD & $\begin{array}{l}\text { May affect recognition by antibodies, located in a "recurrent deletion region", diagnostic real- } \\
\text { time PCR detection failure }\end{array}$ & {$[24,78,156]$} \\
\hline $\mathrm{k} 417 \mathrm{~N}$ & RBD & May escape antibody binding and decrease ACE2 binding & {$[157,158]$} \\
\hline L452R & RBD & $\begin{array}{l}\text { May augment ACE2 binding, increase antibody neutralization, and permit cellular immunity } \\
\text { escape }\end{array}$ & {$[159,160]$} \\
\hline S477N & RBD & May increase ACE2 binding and reduce neutralization by antibodies and convalescent sera & {$[161,162]$} \\
\hline E484K & RBD & $\begin{array}{l}\text { May reduce convalescent serum neutralization (immune escape) and increase ACE2 binding. It } \\
\text { has been associated with reinfection. }\end{array}$ & {$[64,163-165]$} \\
\hline N501Y & RBD & May increase ACE2 binding and antibody recognition & [64] \\
\hline D614G & Spike & May increase infectivity & [163] \\
\hline $\mathrm{P} 681 \mathrm{H}$ & Spike & $\begin{array}{l}\text { May reduce antibody recognition, be important for immune recognition, and increase the rate of } \\
\text { S1-S2 cleavage }\end{array}$ & {$[159,159,159]$} \\
\hline
\end{tabular}

regions of the $\mathrm{S}$ protein of SARS-Co-V-2 might limit the influence of mutations on cellular immunity [114]. Furthermore, for circulating variants such as Beta and Gamma, it is reasonable to predict that T-cell-mediated immunity elicited by infection would be protective. Motozono and colleagues found that the L452R and Y453F mutations in the B.1.427/B.1.429 and B.1.298 variants contribute to escape from HLA-A24-medicated cellular immunity [115]. This implies a role of CTL responses in the control and evolution of SARS-CoV-2 and vice versa. Another study showed no difference in $\mathrm{CD}^{+}{ }^{+} \mathrm{T}$ cell activation in response to the Alpha and Beta variants [116]. Furthermore, the presence of SARS-CoV-2-specific memory $\mathrm{T}$ cells has been detected 10 months after infection [115, 117].

There are also different strategies that SARS-CoV-2 uses to escape the innate immune response [118]. It has been demonstrated that SARS-CoV-2 is sensed by innate immune sensors such as TLR-3 and TLR-7 [119, 120] and that the Nsp8, ORF9b, N, and M proteins of SARSCoV-2 are involved in escape from innate immune sensors. Nsp8 suppresses the MDA5-dependent IFN signaling pathway by direct binding to MDA5 CARD and blocking K63-linked polyubiquitination [121]. ORF9b antagonizes the type I IFN pathway via association with translocator of outer membrane 70 (TOM70), a critical mitochondrial import receptor regulating IFN responses [122]. A recent study showed that SARS-CoV-2 N suppresses the phosphorylation and nuclear translocation of STAT1 and STAT2, thus interfering with the IFN signaling pathway [123]. Moreover, another study has shown that the SARS-CoV-2 M protein suppresses type I and III IFN production. SARS-CoV-2 $\mathrm{M}$ binds directly to essential molecules of the cytosolic viral RNA sensing pathway, such as RIG-I, MDA5, MAVS, and TBK1, and prevents their interaction [124].

\section{Risk of hospitalization and mortality}

VOCs can spread quickly in communities, leading to an increased number of COVID-19 patients, a higher hospitalization rate, increased pressure on healthcare systems, and higher mortality rates, mainly in older individuals with comorbidities [49]. A matched cohort study was performed in the UK by Challen et al. to evaluate changes in mortality rates related to the Alpha variant. The mortality hazard ratio was estimated to be 1.64 (95\% CI 1.32-2.04) in patients who tested positive for novel variants, with 2.5-4.1 deaths per 1000 confirmed cases [66]. Davis et al. estimated a $61 \%$ higher mortality rate for B.1.1.7 than for the previous variants [125]. Furthermore, B.1.1.7 was associated with a ??relative risk?? (RR) of hospital admission of 1.42 (95\% CI 1.25-1.60; $p<0.0001)$ in Denmark. Moreover, the inhospital mortality risk was estimated to be $20 \%$ higher for the Beta variant (adjusted OR: 1.2, 95\% CI 1.2-1.3) [50].

A meta-analysis data showed a strong correlation between age and infection fatality rate (IFR) in COVID-19 cases. The age-specific IFR was estimated to be $0.002 \%, 0.01 \%, 0.4 \%$, $1.4 \%, 4.6 \%$, and $15 \%$ at the age of $10,25,55,65,75$, and 85 , respectively [126]. There are also differences in mortality among different racial and ethnic groups. For instance, an analysis of the COVID-19 mortality cumulative incidence (CmI) demonstrated that Blacks/African Americans have $34 \%$ of the total mortality in the United States despite representing only $13 \%$ of the population. The COVID-19 CFR was also higher among Blacks/African Americans relative to Whites [127]. No peer-reviewed articles are available for the CFR of the Delta variant.

A higher hospitalization risk was observed in American patients infected with Gamma (HR 3.17, 95\% CI 2.15-4.67), Beta (HR: 2.97, 95\% CI 1.65-5.35), Delta (HR: 2.30, 95\% CI 1.69-3.15), and Alpha (HR 1.59, 95\% CI 1.26-1.99) than in those infected with a non-VOC lineage [128]. The 
hospitalization risk after infection with the Delta variant has also been reported for a cohort in Scotland (HR 1.85, 95\% CI 1.39-2.47) [129] and England (HR 2.61, 95\% CI 1.56-4.36) [130]. In a study conducted in Singapore, the Delta variant was associated with indicators of higher disease severity, such as oxygen requirement, ICU admission, or death (adjusted odds ratio (AOR) 4.90, [95\% CI 1.43-30.78]) [131].

\section{Diagnostics}

Specific detection of variants is done by various methods [132]. Laboratories may choose one or more methods based on the facilities and technology available, their contacts with partner laboratories, and the number of trained specialists, as well as their epidemiological goals, such as disease control and monitoring [30, 133, 134]. These methods include complete sequencing of the viral genome, partial gene sequencing, and real-time-PCR-based screening techniques [135]. Sequencing is the gold standard and is a reliable and accurate method for identifying variants. In this case, the whole viral genome is sequenced by a tailed-amplicon approach or shotgun sequencing, and the results are compared with other data in SARS-CoV-2 databases [136]. This method can be used as a reference method without prior knowledge of specific mutations in the viral genome. Partial next-generation sequencing or Sanger sequencing is an alternative way to identify VOCs [137] by limiting sequencing to the $\mathrm{S}$ gene. Although this technique shares the disadvantages of wholegenome sequencing in terms of high cost and the need for sophisticated bioinformatics analysis and advanced equipment, it can be done more quickly. Several multiplex and allele-specific real-time-PCR-based techniques have been proposed for screening variants [135]. In the spike $\Delta 69-70$ screening test, $\mathrm{S}$ gene target failure (SGTF) is seen with some VOCs (such as the Alpha variant) due to the deletion [136]. The TaqPath commercial multiplex real-time PCR kit, which simultaneously identifies three genes - N, ORF1ab, and $\mathrm{S}$ - is affected by SGFT but can still be used to screen for variant B1.1.7 [138]. It should be noted that SGFT is observed not only with the B1.1.7 variant but with other variants as well.

As an alternative to sequencing, mutation screening tests have been developed. For example, Vogels et al. designed a screening test for the Alpha, Beta, and Gamma variants in which two distinct regions including $\Delta 3675-3677$ of ORF $1 \mathrm{ab}$ and $\Delta 69-70$ of $\mathrm{S}$ are targeted in a real-time-PCRbased assay [139]. The ORF1ab gene deletion is seen in all three of the above-mentioned VOCs, whereas the 69-70 gene deletion is seen only in the UK variant.

Multiplex S gene $\Delta 69-70$ and N501Y real-time PCR is also used as a practical test to screen for VOCs. The difference between this method and the test described above is that N501Y has been selected as a common target in the Alpha, Beta, and Gamma VOCs [140]. The N501Y screening test detects N501Y in three variants of concern by allelespecific PCR [141]. In the N501Y and A570D screening test, A570D is present only in the Alpha variant, whereas N501Y is present in the Alpha, Beta, and Gamma variants [142]. An E484K screening test is designed to detect the E484K amino acid change in the P1 and B1.135 variants and in some B1.1.7 variants that also have this mutation [143]. In addition, some commercial screening kits detect variants by analyzing all of the significant mutations using real-time PCR followed by melting curve analysis [144].

\section{Conclusions}

Theoretically, variants can arise by intra-host evolution in immunocompromised individuals (quasispecies evolution) or by antigenic evolution under selective pressure in immunocompetent individuals [30]. Since only a small fraction of all SARS-CoV-2-confirmed specimens have been sequenced, the data favoring one or the other of these hypotheses might be strongly influenced by sampling bias [145].

To estimate the impact of a new variant on clinical presentation, patient prognosis, and mortality rates, it is important to control for all potential sources of bias (confounding factors), including time of sampling, age, sex, geographical location, ethnicity, and other factors [51, 66]. Relaxation of social distancing provides an opportunity for SARS-CoV-2 to circulate freely in the population, increasing the chance of the emergence of novel and highly transmissible VOCs $[52,59]$. Changes in symptoms associated with novel variants might require changes in the testing and surveillance infrastructure.

Currently, randomized experimental studies to evaluate the effect of mutations on SARS-CoV-2 transmissibility are not possible, so we must rely on evidence from observational studies. Furthermore, accurate contact tracing and outbreakreported data are essential for obtaining precise information about the relative transmissibility of VOCs [48, 146, 147]. Finally, the appearance of several new mutations over a short period is expected [67]. Particular mutations in the RBM of the spike have been reported to affect infectivity, transmissibility, pathogenesis, and immune evasion [43]. Hence, an agile and robust broad-based global genomic surveillance network for monitoring multiple emerging VOC lineages is needed to guide efficient management of possible outbreaks. SARS-CoV-2 circulates freely in communities, increasing the chance for new variants with increased transmissibility to emerge that will threaten the success of vaccination programs for controlling the pandemic. Any significant mutation that changes the structure of the spike can potentially affect adaptation of the virus to human hosts and lead to 
vaccine resistance and reinfection. Therefore, to stop the emergence of new VOCs, a robust worldwide vaccination program is essential.

A problematic issue is the accumulation of changes in surface glycoproteins of coronaviruses, which may be called antigenic evolution, which can result in reduced neutralization of the virus over time. Antigenic evolution of the viral spike in human coronavirus $229 \mathrm{E}$, especially in the receptorbinding domain, is responsible for the decreased neutralization of "future" viruses. If it is possible to extrapolate these findings to other coronaviruses such as SARS-CoV-2, it may be necessary to update SARS-CoV-2 vaccines on a regular basis [148].

The use of replication-competent chimeric viruses based on vesicular stomatitis virus (VSV) is another issue that needs to be addressed. Experiments on escape mutants selected in the presence of monoclonal antibodies in vitro are not representative of what actually happens in the SARSCoV-2 life cycle, since SARS-CoV-2 has a proofreading enzyme complex, whereas VSV does not have proofreading ability [149].

In general, available, accessible, and affordable vaccines should be a top priority all over the world. Some highincome countries have pre-ordered up to nine doses per person, while resource-limited countries might have to wait until 2023 or 2024 for vaccination. This unbalanced distribution of vaccines will result in the establishment of vaccinated populations in some geographical regions and unvaccinated populations in others, and this lack of immunization of people in low-income countries will continue to result in the generation of novel immune-escape variants, which will ultimately circulate in the international population and reinfect vaccinated individuals in developed countries. Indeed, this phenomenon is already being observed $[150,151]$.

It is reasonable to assume that there is a limit to the number of possible SARS-CoV-2 mutations and new variants, but no one knows exactly what this limit is. If a singlestranded RNA has 10,000 base pairs, $4^{5000}$ different genome sequences are theoretically possible. If we extrapolate this to the SARS-CoV-2 genome, which is around $30 \mathrm{~kb}$ in length, $4^{14,941}$ different sequences are possible [152]. Furthermore, when deletions and insertions are also considered, the number of further possibilities increases enormously. However, most of these theoretical combinations would not be viable, and many individual changes might be neutral in their effect on viral properties.

Since we are unable to predict future mutations and emerging variants of SARS-CoV-2, all we can do is continue surveillance of existing variants. SARS-CoV-2 is under strong selective pressure from two directions: immune responses and treatments. Both natural infection and vaccination can result in an effective immune response, but protection by neutralizing antibodies may be diminished with new vaccination-escape variants [153]. Strong selective pressure can suppress virus replication, whereas weak selective pressure can give the virus a chance to replicate freely. The situation becomes worse when an inadequate neutralizing antibody response is elicited by weak vaccines or there is an extended time between doses of the vaccine. Such conditions favor the emergence of new variants of SARS-CoV-2.

Acknowledgements We are grateful to Pasteur Institute of Iran for financial support of this study.

Author contributions M.S.V. and A.M. designed the study. M.F., S.M.S., M.S.P., T.J., Z.S., and A.M. wrote the draft. K.A., M.S.V., and A.M. edited and revised the manuscript. M.S.V., M.F., and A.M. contributed to the final version of the manuscript.

Funding This work was supported by Pasteur Institute of Iran [grant number 1824].

\section{Declarations}

Conflict of interest The authors declare that they have no conflict of interest related to this work.

\section{References}

1. WHO. COVID-19 weekly epidemiological update, 27 July 2021. 2021.

2. Neerukonda SN, Katneni U (2020) A review on SARS-CoV-2 virology, pathophysiology, animal models, and anti-viral interventions. Pathogens 9(6):426

3. Cheng A, Zhang W, Xie Y, Jiang W, Arnold E, Sarafianos SG et al (2005) Expression, purification, and characterization of SARS coronavirus RNA polymerase. Virology 335(2):165-176

4. Ferron F, Subissi L, Silveira De Morais AT, Le NTT, Sevajol M, Gluais L et al (2018) Structural and molecular basis of mismatch correction and ribavirin excision from coronavirus RNA. Proc Natl Acad Sci 115(2):E162-E171

5. Sender R, Bar-On YM, Gleizer S, Bernshtein B, Flamholz A, Phillips R et al (2021) The total number and mass of SARSCoV-2 virions. Proc Natl Acad Sci 118:25

6. COVID-19 Treatment Guidelines Panel. Coronavirus Disease 2019 (COVID-19) Treatment Guidelines; (April 21, 2020). Available from: https://www.covid19treatmentguidelines.nih. gov/.

7. Maurin M, Fenollar F, Mediannikov O, Davoust B, Devaux C, Raoult D (2021) Current status of putative animal sources of SARS-CoV-2 infection in humans: wildlife, domestic animals and pets. Microorganisms. 9(4):868

8. Boechat JL, Chora I, Morais A, Delgado L (2021) The immune response to SARS-CoV-2 and COVID-19 immunopathologycurrent perspectives. Pulmonology. https://doi.org/10.1016/j. pulmoe.2021.03.008

9. Focosi D, Maggi F (2021) Neutralising antibody escape of SARS-CoV-2 spike protein: risk assessment for antibody-based Covid-19 therapeutics and vaccines. Rev Med Virol. https://doi. org/10.1002/rmv.2231

10. Mascola JR, Graham BS, Fauci AS (2021) SARS-CoV-2 viral variants-tackling a moving target. JAMA 325(13):1261-1262 
11. SARS-CoV-2 Variant Classifications and Definitions23 Sep 2021. Available from: https://www.cdc.gov/coronavirus/2019ncov/cases-updates/variant-surveillance/variant-info.html\# Consequence.

12. Andrew Rambaut NL, Oliver Pybus, Wendy Barclay, Jeff Barrett, Alesandro Carabelli, Tom Connor, Tom Peacock, David L Robertson, Erik Volz. Preliminary genomic characterisation of an emergent SARS-CoV-2 lineage in the UK defined by a novel set of spike mutations2020. Available from: https://virol ogical.org/t/preliminary-genomic-characterisation-of-an-emerg ent-sars-cov-2-lineage-in-the-uk-defined-by-a-novel-set-ofspike-mutations $/ 563$.

13. Tegally H, Wilkinson E, Giovanetti M, Iranzadeh A, Fonseca V, Giandhari J, et al (2020) Emergence and rapid spread of a new severe acute respiratory syndrome-related coronavirus 2 (SARS-CoV-2) lineage with multiple spike mutations in South Africa. medRxiv https://doi.org/10.1101/2020.12.21.20248640

14. Naveca F, Nascimento V, Souza V, Corado A, Nascimento F, Silva G, et al. Phylogenetic relationship of SARS-CoV-2 sequences from Amazonas with emerging Brazilian variants harboring mutations E484K and N501Y in the Spike protein. Virological org Available at: https://virological.org/t/phylo genetic-relationship-of-sars-cov-2-sequences-from-amazo nas-with-emerging-brazilian-variants-harboring-mutationse484k-and-n501y-in-the-spike-protein/585. 2021.

15. B.1.617 variant first identified in India classified as variant of global concern [press release]. ctvnews.ca, 2021

16. Deng X, Garcia-Knight MA, Khalid MM, Servellita V, Wang C, Morris MK et al (2021) Transmission, infectivity, and neutralization of a spike L452R SARS-CoV-2 variant. Cell. https:// doi.org/10.1016/j.cell.2021.04.025

17. Gravagnuolo AM, Faqih L, Cronshaw C, Wynn J, Burglin L, Klapper P, et al (2021) Epidemiological investigation of new SARS-CoV-2 variant of concern 202012/01 in England. medRxiv https://doi.org/10.1101/2021.01.14.21249386

18. Davies NG, Jarvis CI, van Zandvoort K, Clifford S, Sun FY, Funk S, et al (2021) Increased mortality in community-tested cases of SARS-CoV-2 lineage B.1.1.7. Nature 593(7858):270-4

19. Volz E, Mishra S, Chand M, Barrett JC, Johnson R, Geidelberg $\mathrm{L}$, et al (2021) Transmission of SARS-CoV-2 Lineage B. 1.1. 7 in England: Insights from linking epidemiological and genetic data. medRxiv. https://doi.org/10.1101/2020.12.30.20249034

20. Graham MS, Sudre CH, May A, Antonelli M, Murray B, Varsavsky T et al (2021) Changes in symptomatology, reinfection, and transmissibility associated with the SARS-CoV-2 variant B. 1.1. 7: an ecological study. Lancet Public Health. https:// doi.org/10.1016/S2468-2667(21)00055-4

21. Mahase E (2021) Covid-19: Sore throat, fatigue, and myalgia are more common with new UK variant. BMJ. https://doi.org/ 10.1136/bmj.n288

22. Tian F, Tong B, Sun L, Shi S, Zheng B, Wang Z et al (2021) Mutation N501Y in RBD of Spike Protein Strengthens the Interaction between COVID-19 and its Receptor ACE2. BioRxiv. https://doi.org/10.1101/2021.02.14.431117

23. Tada T, Dcosta BM, Samanovic-Golden M, Herati RS, Cornelius A, Mulligan MJ, et al (2021) Neutralization of viruses with European, South African, and United States SARS-CoV-2 variant spike proteins by convalescent sera and BNT162b2 mRNA vaccine-elicited antibodies. bioRxiv https://doi.org/ 10.1101/2021.02.05.430003

24. Ascoli CA (2021) Could mutations of SARS-CoV-2 suppress diagnostic detection? Nat Biotechnol 39(3):274-275

25. Wise J (2021) Covid-19: The E484K mutation and the risks it poses. BMJ. https://doi.org/10.1136/bmj.n359
26. Makowski L, Olson-Sidford W, Weisel J (2021) Biological and clinical consequences of integrin binding via a rogue RGD motif in the SARS CoV-2 spike protein. Viruses 13(2):146

27. Galloway SE, Paul P, MacCannell DR, Johansson MA, Brooks JT, MacNeil A et al (2021) Emergence of SARS-CoV-2 b. 1.1. 7 lineage - united states, December 29, 2020-January 12, 2021. Morbid Mortal Week Rep 70(3):95

28. Pereira F (2021) SARS-CoV-2 variants combining spike mutations and the absence of ORF8 may be more transmissible and require close monitoring. Biochem Biophys Res Commun 550:8-14

29. Ramírez JD, Muñoz M, Patiño LH, Ballesteros N, PanizMondolfi A (2021) Will the emergent SARS-CoV2 B. 1.1. 7 lineage affect molecular diagnosis of COVID-19? J Med Virol 93(5):2566-2568

30. Tegally H, Wilkinson E, Giovanetti M, Iranzadeh A, Fonseca V, Giandhari J et al (2021) Detection of a SARS-CoV-2 variant of concern in South Africa. Nature 592(7854):438-443

31. Peñarrubia L, Ruiz M, Porco R, Rao SN, Juanola-Falgarona M, Manissero D et al (2020) Multiple assays in a real-time RT-PCR SARS-CoV-2 panel can mitigate the risk of loss of sensitivity by new genomic variants during the COVID-19 outbreak. Int J Infect Dis 97:225-229

32. Zhou D, Dejnirattisai W, Supasa P, Liu C, Mentzer AJ, Ginn $\mathrm{HM}$ et al (2021) Evidence of escape of SARS-CoV-2 variant B. 1.351 from natural and vaccine-induced sera. Cell. 184(9):2348-23461.e6

33. Tegally H, Wilkinson E, Giovanetti M, Iranzadeh A, Fonseca V, Giandhari J, et al. (2020) Emergence and rapid spread of a new severe acute respiratory syndrome-related coronavirus 2 (SARS-CoV-2) lineage with multiple spike mutations in South Africa. medRxiv https://doi.org/10.1101/2020.12.21.20248640

34. Wang P, Nair MS, Liu L, Iketani S, Luo Y, Guo Y et al (2021) Antibody resistance of SARS-CoV-2 variants B. 1.351 and B. 1.1. 7. Nature. 593(7857):130-135

35. Faria NR, Mellan TA, Whittaker C, Claro IM, Candido DdS, Mishra S et al (2021) Genomics and epidemiology of the P 1 SARS-CoV-2 lineage in Manaus, Brazil. Science 372(6544):815-821

36. Freitas AR, Lemos DR, Beckedorff OA, Cavalcante LP, Siqueira AM, Mello RC, et al. (2021) The increase in the risk of severity and fatality rate of covid-19 in southern Brazil after the emergence of the Variant of Concern (VOC) SARS-CoV-2 P. 1 was greater among young adults without pre-existing risk conditions. medRxiv https://doi.org/10.1101/2021.04.13.21255 281

37. Faria NR, Mellan TA, Whittaker C, Claro IM, Candido DDS, Mishra S, et al (2021) Genomics and epidemiology of the P.1 SARS-CoV-2 lineage in Manaus, Brazil. Science 372(6544):815-21

38. Hirotsu Y, Omata M (2021) Discovery of a SARS-CoV-2 variant from the P.1 lineage harboring K417T/E484K/N501Y mutations in Kofu, Japan. J Infect. 82(6):276-316

39. Wang P, Casner RG, Nair MS, Wang M, Yu J, Cerutti G et al (2021) Increased resistance of SARS-CoV-2 variant P.1 to antibody neutralization. Cell Host Microbe. 29(5):747-751

40. Lamarca AP, de Almeida LG, da Silva Francisco R, Lima LFA, Scortecci KC, Perez VP, et al. (2021) Genomic surveillance of SARS-CoV-2 tracks early interstate transmission of P. 1 lineage and diversification within P. 2 clade in Brazil. medRxiv. https:// doi.org/10.1101/2021.03.21.21253418

41. Resende PC, Delatorre E, Gräf T, Mir D, Motta FC, Appolinario LR et al (2020) Evolutionary dynamics and dissemination pattern of the SARS-CoV-2 lineage B. 1.1. 33 during the early pandemic phase in Brazil. Front Microbiol. https://doi.org/10.3389/fmicb. 2020.615280 
42. Lopez-Rincon A, Perez-Romero C, Tonda A, Mendoza-Maldonado L, Claassen E, Garssen J, et al (2021) Design of specific primer sets for the detection of B. 1.1. 7, B. 1.351 and P. 1 SARSCoV-2 variants using deep learning. bioRxiv https://doi.org/10. 1101/2021.01.20.427043

43. Cherian S, Potdar V, Jadhav S, Yadav P, Gupta N, Das M et al (2021) Convergent evolution of SARS-CoV-2 spike mutations, L452R, E484Q and P681R, in the second wave of COVID-19 in Maharashtra, India. bioRxiv. https://doi.org/10.1101/2021.04.22. 440932

44. Organization WH (2021) COVID-19 weekly epidemiological update, 9 May 2021

45. Organization WH (2021) COVID-19 weekly epidemiological update, edition 42, 01 June 2021

46. Ranjan R, Sharma A, Verma MK (2021) Characterization of the second wave of COVID-19 in India. medRxiv. https://doi.org/10. 1101/2021.04.17.21255665

47. England PH (2021) SARS-CoV-2 variants of concern and variants under investigation in England. Techn Brief 16

48. Volz E, Mishra S, Chand M, Barrett JC, Johnson R, Geidelberg $\mathrm{L}$ et al (2021) Assessing transmissibility of SARS-CoV-2 lineage B117 in England. Nature 593(7858):266-269

49. European Centre for Disease Prevention and Control (2021) Risk related to spread of new SARS-CoV-2 variants of concern in the EU/EEA. First update - 21 January. ECDC: Stockholm

50. WHO (2021) Weekly epidemiological update on COVID-19. 13 April 2021

51. Ong SWX, Young BE, Lye DC (2021) Lack of detail in population-level data impedes analysis of SARS-CoV-2 variants of concern and clinical outcomes. Lancet Infect Dis. https://doi.org/ 10.1016/S1473-3099(21)00201-2

52. Davies NG, Abbott S, Barnard RC, Jarvis CI, Kucharski AJ, Munday JD et al (2021) Estimated transmissibility and impact of SARS-CoV-2 lineage B. 1.1. 7 in England. Science. 372:6538

53. Leung K, Shum MH, Leung GM, Lam TT, Wu JT (2021) Early transmissibility assessment of the N501Y mutant strains of SARS-CoV-2 in the United Kingdom, October to November 2020. Eurosurveillance 26(1):2002106

54. Davies NG, Jarvis CI, van Zandvoort K, Clifford S, Sun FY, Funk $S$ et al (2021) Increased mortality in community-tested cases of SARS-CoV-2 lineage B.1.1.7. Nature 593(7858):270-274

55. Schuit M, Biryukov J, Beck K, Yolitz J, Bohannon J, Weaver W, et al (2021) The stability of an isolate of the SARS-CoV-2 B.1.1.7 lineage in aerosols is similar to three earlier isolates. $\mathrm{J}$ Infect Dis

56. Liu Y, Liu J, Plante KS, Plante JA, Xie X, Zhang X, et al (2021) The N501Y spike substitution enhances SARS-CoV-2 transmission. bioRxiv. https://doi.org/10.1101/2021.03.08.434499

57. Johnson BA, Xie X, Bailey AL, Kalveram B, Lokugamage KG, Muruato A et al (2021) Loss of furin cleavage site attenuates SARS-CoV-2 pathogenesis. Nature 591(7849):293-299

58. Saito A, Irie T, Suzuki R, Maemura T, Nasser H, Uriu K, et al (2021) SARS-CoV-2 spike P681R mutation, a hallmark of the Delta variant, enhances viral fusogenicity and pathogenicity. bioRxiv https://doi.org/10.1101/2021.06.17.448820

59. Felipe N, Valdinete N, Victor S, André C, Fernanda N, George $S$, et al (2021) Nature Portfolio

60. Naveca F, Nascimento V, Souza V, Corado A, Nascimento F, Silva G, et al (2021) COVID-19 epidemic in the Brazilian state of Amazonas was driven by long-term persistence of endemic SARS-CoV-2 lineages and the recent emergence of the new Variant of Concern P. 1.

61. Coutinho RM, Marquitti FMD, Ferreira LS, Borges ME, da Silva RLP, Canton O, et al (2021) Model-based evaluation of transmissibility and reinfection for the P 1 variant of the SARS-CoV-2. medRxiv https://doi.org/10.1101/2021.03.03.21252706
62. Faria NR, Mellan TA, Whittaker C, Claro IM, Candido DDS, Mishra S, et al (2021) Genomics and epidemiology of a novel SARS-CoV-2 lineage in Manaus, Brazil. medRxiv

63. Nelson G, Buzko O, Spilman P, Niazi K, Rabizadeh S, SoonShiong P (2021) Molecular dynamic simulation reveals E484K mutation enhances spike RBD-ACE2 affinity and the combination of E484K, K417N and N501Y mutations (501Y.V2 variant) induces conformational change greater than N501Y mutant alone, potentially resulting in an escape mutant. bioRxiv https://doi.org/10.1101/2021.01.13.426558

64. Singh J, Rahman SA, Ehtesham NZ, Hira S, Hasnain SE (2021) SARS-CoV-2 variants of concern are emerging in India. Nature Med 27:1131-1133

65. gov.wales. Technical Advisory Group: advice from TAG and the Chief Scientific Advisor for Health on the Delta Variant (18 June 2021). Available from: https://gov.wales/technical-advis ory-group-advice-tag-and-chief-scientific-advisor-health-deltavariant.

66. Challen R, Brooks-Pollock E, Read JM, Dyson L, TsanevaAtanasova K, Danon L (2021) Risk of mortality in patients infected with SARS-CoV-2 variant of concern 202012/1: matched cohort study. BMJ. 372:n579

67. Deng X, Garcia-Knight MA, Khalid MM, Servellita V, Wang C, Morris MK, et al (2021) Transmission, infectivity, and antibody neutralization of an emerging SARS-CoV-2 variant in California carrying a L452R spike protein mutation. medRxiv https://doi.org/10.1101/2021.03.07.21252647

68. McCallum M, Bassi J, Marco A, Chen A, Walls AC, Iulio JD, et al (2021) SARS-CoV-2 immune evasion by variant B1427/ B1429. bioRxiv. https://doi.org/10.1101/2021.03.31.437925

69. Ferreira I, Datir R, Papa G, Kemp S, Meng B, Rakshit P, et al (2021) SARS-CoV-2 B.1.617 emergence and sensitivity to vaccine-elicited antibodies. bioRxiv https://doi.org/10.1101/ 2021.05.08.443253

70. Yadav PD, Mohandas S, Shete AM, Nyayanit DA, Gupta N, Patil DY, et al (2021) SARS CoV-2 variant B.1.617.1 is highly pathogenic in hamsters than B.1 variant. bioRxiv. https://doi. org/10.1101/2021.05.05.442760

71. Control ECfDPa. Emergence of SARS-CoV-2 B.1.617 variants in India and situation in the EU/EEA. ECDC: Stockholm. 11 May 2021

72. Cele S, Gazy I, Jackson L, Hwa S-H, Tegally H, Lustig G, et al (2021) Escape of SARS-CoV-2 501Y.V2 variants from neutralization by convalescent plasma. medRxiv https://doi. org/10.1101/2021.01.26.21250224

73. Edridge AWD, Kaczorowska J, Hoste ACR, Bakker M, Klein M, Loens K et al (2020) Seasonal coronavirus protective immunity is short-lasting. Nat Med 26(11):1691-1693

74. Aldridge R, Lewer D, Beale S, Johnson A, Zambon M, Hayward A, et al (2020) Seasonality and immunity to laboratoryconfirmed seasonal coronaviruses (HCoV-NL63, HCoV-OC43, and $\mathrm{HCoV}-229 \mathrm{E})$ : results from the Flu Watch cohort study [version 2; peer review: 2 approved]. Welcome Open Res https://doi.org/10.12688/wellcomeopenres.15812.2

75. McCarthy KR, Rennick LJ, Nambulli S, Robinson-McCarthy LR, Bain WG, Haidar G et al (2021) Recurrent deletions in the SARS-CoV-2 spike glycoprotein drive antibody escape. Science 371(6534):1139-1142

76. Garcia-Beltran WF, Lam EC, Astudillo MG, Yang D, Miller TE, Feldman J et al (2021) COVID-19-neutralizing antibodies predict disease severity and survival. Cell 184(2):476-88.e11

77. Garcia-Beltran WF, Lam EC, St. Denis K, Nitido AD, Garcia ZH, Hauser BM, et al (2021) Multiple SARS-CoV-2 variants escape neutralization by vaccine-induced humoral immunity. Cell. https://doi.org/10.1016/j.cell.2021.03.013 
78. Shen X, Tang H, McDanal C, Wagh K, Fischer W, Theiler J et al (2021) SARS-CoV-2 variant B117 is susceptible to neutralizing antibodies elicited by ancestral spike vaccines. Cell Host Microbe 29(4):529-539

79. Muik A, Wallisch AK, Sänger B, Swanson KA, Mühl J, Chen $\mathrm{W}$ et al (2021) Neutralization of SARS-CoV-2 lineage B.1.1.7 pseudovirus by BNT162b2 vaccine-elicited human sera. Science. 371(6534):1152-1153

80. Wu K, Werner AP, Moliva JI, Koch M, Choi A, Stewart-Jones GBE, et al (2021) mRNA-1273 vaccine induces neutralizing antibodies against spike mutants from global SARS-CoV-2 variants. bioRxiv https://doi.org/10.1101/2021.01.25.427948

81. Hoffmann M, Arora P, Groß R, Seidel A, Hörnich BF, Hahn AS et al (2021) SARS-CoV-2 variants B1351 and P1 escape from neutralizing antibodies. Cell. https://doi.org/10.1016/j. cell.2021.03.036

82. Edara VV, Norwood C, Floyd K, Lai L, Davis-Gardner ME, Hudson WH et al (2021) Infection- and vaccine-induced antibody binding and neutralization of the B1351 SARS-CoV-2 variant. Cell Host Microbe. https://doi.org/10.1016/j.chom. 2021.03.009

83. Zhou D, Dejnirattisai W, Supasa P, Liu C, Mentzer AJ, Ginn HM et al (2021) Evidence of escape of SARS-CoV-2 variant B.1.351 from natural and vaccine-induced sera. Cell. https://doi.org/10. 1016/j.cell.2021.02.037

84. Dong J, Zost SJ, Greaney AJ, Starr TN, Dingens AS, Chen EC, et al (2021) Genetic and structural basis for recognition of SARSCoV-2 spike protein by a two-antibody cocktail. bioRxiv. https:// doi.org/10.1101/2021.01.27.428529

85. Wang P, Liu L, Iketani S, Luo Y, Guo Y, Wang M, et al (2021) Increased resistance of SARS-CoV-2 variants B.1.351 and B.1.1.7 to antibody neutralization. bioRxiv https://doi.org/10. 1016/j.chom.2021.04.007

86. Wibmer CK, Ayres F, Hermanus T, Madzivhandila M, Kgagudi P, Oosthuysen B et al (2021) SARS-CoV-2 501Y.V2 escapes neutralization by South African COVID-19 donor plasma. Nature Med 27(4):622-625

87. McCallum M, Bassi J, Marco AD, Chen A, Walls AC, Iulio JD, et al (2021) SARS-CoV-2 immune evasion by variant B1427/ B1429. bioRxiv https://doi.org/10.1101/2021.03.31.437925

88. Shen X, Tang H, Pajon R, Smith G, Glenn GM, Shi W et al (2021) Neutralization of SARS-CoV-2 Variants B1429 and B1351. New Engl J Med. https://doi.org/10.1056/NEJMc21037 40

89. Tchesnokova V, Kulakesara H, Larson L, Bowers V, Rechkina E, Kisiela D, et al (2021) Acquisition of the L452R mutation in the ACE2-binding interface of Spike protein triggers recent massive expansion of SARS-Cov-2 variants. bioRxiv https://doi.org/10. $1101 / 2021.02 .22 .432189$

90. Jacobson KB, Pinsky BA, Rath MEM, Wang H, Miller JA, Skhiri M, et al (2021) Post-vaccination SARS-CoV-2 infections and incidence of the B.1.427/B.1.429 variant among healthcare personnel at a northern California academic medical center. medRxiv. https://doi.org/10.1101/2021.04.14.21255431

91. Javanmardi K, Chou C-W, Terrace CI, Annapareddy A, Kaoud TS, Guo Q, et al (2021) Rapid characterization of spike variants via mammalian cell surface display. bioRxiv. https://doi.org/10. 1101/2021.03.30.437622.

92. Edara V-V, Lai L, Sahoo MK, Floyd K, Sibai M, Solis D, et al. (2021) Infection and vaccine-induced neutralizing antibody responses to the SARS-CoV-2 B.1.617.1 variant. bioRxiv. https:// doi.org/10.1101/2021.05.09.443299

93. Yadav PD, Sapkal GN, Abraham P, Ella R, Deshpande G, Patil DY, et al. (2021) Neutralization of variant under investigation B.1.617 with sera of BBV152 vaccinees. bioRxiv. https://doi. org/10.1101/2021.04.23.441101
94. Callaway E, Mallapaty S (2021) Novavax offers first evidence that COVID vaccines protect people against variants. Nature 590(7844): 17

95. Emary KRW, Golubchik T, Aley PK, Ariani CV, Angus B, Bibi S et al (2021) Efficacy of ChAdOx1 nCoV-19 (AZD1222) vaccine against SARS-CoV-2 variant of concern 202012/01 (B.1.1.7): an exploratory analysis of a randomised controlled trial. Lancet. 397(10282):1351-1362

96. Nasreen S, Chung H, He S, Brown KA, Gubbay JB, Buchan SA, et al. (2021) Effectiveness of COVID-19 vaccines against variants of concern in Ontario, Canada. medRxiv. https://doi.org/10. $1101 / 2021.06 .28 .21259420$

97. Lefèvre B, Tondeur L, Madec Y, Grant R, Lina B, van der Werf S, et al. (2021) Impact of B.1.351 (beta) SARS-CoV-2 variant on BNT162b2 mRNA vaccine effectiveness in long-term care facilities of eastern France: a retrospective cohort study. medRxiv. https://doi.org/10.1101/2021.07.28.21261285

98. Chemaitelly H, Yassine HM, Benslimane FM, Al Khatib HA, Tang P, Hasan MR et al (2021) mRNA-1273 COVID-19 vaccine effectiveness against the B.1.1.7 and B.1.351 variants and severe COVID-19 disease in Qatar. Nature Med 27(9):1614-21

99. Seppälä E, Veneti L, Starrfelt J, Danielsen AS, Bragstad K, Hungnes $\mathrm{O}$ et al (2021) Vaccine effectiveness against infection with the Delta (B 1617 2) variant, Norway, April to August 2021. Euro Surveill 26(35):2100793

100. González S, Olszevicki S, Salazar M, Calabria A, Regairaz L, Marín L et al (2021) Effectiveness of the first component of Gam-COVID-Vac (Sputnik V) on reduction of SARS-CoV-2 confirmed infections, hospitalisations and mortality in patients aged 60-79: a retrospective cohort study in Argentina. EClinicalMedicine. https://doi.org/10.1016/j.eclinm.2021.101126

101. Wang L, Zhou T, Zhang Y, Yang ES, Schramm CA, Shi W, et al (2021) Antibodies with potent and broad neutralizing activity against antigenically diverse and highly transmissible SARSCoV-2 variants. bioRxiv https://doi.org/10.1101/2021.02.25. 432969

102. Baum A, Fulton BO, Wloga E, Copin R, Pascal KE, Russo V et al (2020) Antibody cocktail to SARS-CoV-2 spike protein prevents rapid mutational escape seen with individual antibodies. Science 369(6506): 1014-1018

103. Becker M, Dulovic A, Junker D, Ruetalo N, Kaiser PD, Pinilla $\mathrm{YT}$ et al (2021) Immune response to SARS-CoV-2 variants of concern in vaccinated individuals. Nat Commun 12(1):3109

104. Hoffmann M, Hofmann-Winkler H, Krüger N, Kempf A, Nehlmeier I, Graichen L, et al. (2021) SARS-CoV-2 variant B.1.617 is resistant to Bamlanivimab and evades antibodies induced by infection and vaccination. bioRxiv. https://doi.org/ 10.1101/2021.05.04.442663

105. Rathnasinghe R, Jangra S, Cupic A, Martínez-Romero C, Mulder LC, Kehrer T et al (2021) The N501Y mutation in SARS-CoV-2 spike leads to morbidity in obese and aged mice and is neutralized by convalescent and post-vaccination human sera. MedRxiv. https://doi.org/10.1101/2021.01.19.21249592

106. Xie X, Liu Y, Liu J, Zhang X, Zou J, Fontes-Garfias CR et al (2021) Neutralization of SARS-CoV-2 spike 69/70 deletion, E484K and N501Y variants by BNT162b2 vaccine-elicited sera. Nature Med 27(4):620-621

107. Chen RE, Zhang X, Case JB, Winkler ES, Liu Y, VanBlargan LA et al (2021) Resistance of SARS-CoV-2 variants to neutralization by monoclonal and serum-derived polyclonal antibodies. Nat Med 27(4):717-726

108. Wu K, Werner AP, Koch M, Choi A, Narayanan E, Stewart-Jones GBE et al (2021) Serum neutralizing activity elicited by mRNA1273 vaccine. New Engl J Med 384(15):1468-1470

109. Resende PC, Bezerra JF, de Vasconcelos RHT, Arantes I, Appolinario L, Mendonça AC, et al. (2021) Spike E484K mutation in 
the first SARS-CoV-2 reinfection case confirmed in Brazil, 2020. Virological 10

110. Nonaka CK, Franco MM, Gräf T, de Lorenzo Barcia CA, de Ávila Mendonça RN, de Sousa KAF et al (2021) Genomic evidence of SARS-CoV-2 reinfection involving E484K spike mutation, Brazil. Emerg Infect Dis. 27(5):1522-1524

111. Naveca F, da Costa C, Nascimento V, Souza V, Corado A, Nascimento F, et al. (2021) SARS-CoV-2 reinfection by the new Variant of Concern (VOC) P. 1 in Amazonas, Brazil. virological org Preprint available at: https://virological.org/t/sars-cov2-reinfection-by-thenew-variant-of-concern-voc-p-1-in-amazo nas-brazil/596 Available at: https://virological.org/t/sars-cov2-reinfection-by-the-new-variant-of-concern-voc-p-1-in-amazo nas-brazil/596

112. Greaney AJ, Starr TN, Gilchuk P, Zost SJ, Binshtein E, Loes AN et al (2021) Complete mapping of mutations to the SARS-CoV-2 spike receptor-binding domain that escape antibody recognition. Cell Host Microbe 29(1):44-57.e9

113. Thomson EC, Rosen LE, Shepherd JG, Spreafico R, da Silva FA, Wojcechowskyj JA et al (2021) Circulating SARS-CoV-2 spike $\mathrm{N} 439 \mathrm{~K}$ variants maintain fitness while evading antibodymediated immunity. Cell 184(5):1171-87.e20

114. Williams TC, Burgers WA (2021) SARS-CoV-2 evolution and vaccines: cause for concern? Lancet Respir Med 9(4):333-335

115. Motozono C, Toyoda M, Zahradnik J, Ikeda T, Saito A, Tan TS, et al. (2021) An emerging SARS-CoV-2 mutant evading cellular immunity and increasing viral infectivity. bioRxiv. https://doi. org/10.1101/2021.04.02.438288.

116. Geers D, Shamier MC, Bogers S, Hartog Gd, Gommers L, Nieuwkoop NN, et al. (2021) SARS-CoV-2 variants of concern partially escape humoral but not $\mathrm{T}$ cell responses in COVID19 convalescent donors and vaccine recipients. Sci Immunol 6(59):eabj1750

117. Jung JH, Rha M-S, Sa M, Choi HK, Jeon JH, Seok H et al (2021) SARS-CoV-2-specific T cell memory is sustained in COVID-19 convalescent patients for 10 months with successful development of stem cell-like memory T cells. Nat Commun 12(1):4043

118. Kasuga Y, Zhu B, Jang K-J, Yoo J-S (2021) Innate immune sensing of coronavirus and viral evasion strategies. Exp Mol Med 53(5):723-736

119. Zhang Q, Bastard P, Liu Z, Pen JL, Moncada-Velez M, Chen J, et al. (2020)Inborn errors of type I IFN immunity in patients with life-threatening COVID-19. Science. 370(6515):eabd4570

120. van der Made CI, Simons A, Schuurs-Hoeijmakers J, van den Heuvel G, Mantere T, Kersten S et al (2020) Presence of genetic variants among young men with severe COVID-19. JAMA 324(7):663-673

121. Yang Z, Zhang X, Wang F, Wang P, Kuang E, Li X (2020) Suppression of MDA5-mediated antiviral immune responses by NSP8 of SARS-CoV-2. bioRxiv. https://doi.org/10.1101/2020. 08.12.247767

122. Jiang H-w, Zhang H-n, Meng Q-f, Xie J, Li Y, Chen H et al (2020) SARS-CoV-2 Orf9b suppresses type I interferon responses by targeting TOM70. Cell Mol Immunol 17(9):998-1000

123. Mu J, Fang Y, Yang Q, Shu T, Wang A, Huang M et al (2020) SARS-CoV-2 N protein antagonizes type I interferon signaling by suppressing phosphorylation and nuclear translocation of STAT1 and STAT2. Cell Discovery. 6(1):1-4

124. Zheng Y, Zhuang M-W, Han L, Zhang J, Nan M-L, Zhan P et al (2020) Severe acute respiratory syndrome coronavirus 2 (SARS$\mathrm{CoV}-2$ ) membrane (M) protein inhibits type I and III interferon production by targeting RIG-I/MDA-5 signaling. Signal Transduct Target Ther 5(1):1-13

125. Davies NG, Jarvis CI, Edmunds WJ, Jewell NP, DiazOrdaz K, Keogh RH (2021) (2021) Increased mortality in community-tested cases of SARS-CoV-2 lineage B.1.1.7. Nature. 593(7858):270-274

126. Levin AT, Hanage WP, Owusu-Boaitey N, Cochran KB, Walsh SP, Meyerowitz-Katz G (2020) Assessing the age specificity of infection fatality rates for COVID-19: systematic review, meta-analysis, and public policy implications. Eur J Epidemiol 35(12):1123-1138

127. Holmes L Jr, Enwere M, Williams J, Ogundele B, Chavan P, Piccoli $\mathrm{T}$ et al (2020) Black-white risk differentials in COVID-19 (SARS-COV2) Transmission, mortality and case fatality in the United States: translational epidemiologic perspective and challenges. Int J Environ Res Public Health. 17(12):4322

128. Paredes MI, Lunn S, Famulare M, Frisbie LA, Painter I, Burstein R, et al. (2021) Associations between SARS-CoV-2 variants and risk of COVID-19 hospitalization among confirmed cases in Washington State: a retrospective cohort study. medRxiv https:// doi.org/10.1101/2021.09.29.21264272

129. Sheikh A, McMenamin J, Taylor B, Robertson C (2021) SARS-CoV-2 Delta VOC in Scotland: demographics, risk of hospital admission, and vaccine effectiveness. Lancet 397(10293):2461-2462

130. England PH (2021) SARS-CoV-2 variants of concern and variants under investigation in England. Techn Brief

131. Ong SWX, Chiew CJ, Ang LW, Mak T-M, Cui L, Toh MPH, et al (2021) Clinical and virological features of SARS-CoV-2 variants of concern: a retrospective cohort study comparing B. 1.1. 7 (Alpha), B. 1.315 (Beta), and B. 1.617. 2 (Delta)

132. Walensky RP, Walke HT, Fauci AS (2021) SARS-CoV-2 variants of concern in the United States-Challenges and opportunities. JAMA 325(11):1037-1038

133. Guo S, Liu K, Zheng J (2021) The genetic variant of SARSCoV-2: would It matter for controlling the devastating pandemic? Int J Biol Sci 17(6): 1476

134. Abdool Karim SS, de Oliveira T (2021) New SARS-CoV-2 variants-clinical, public health, and vaccine implications. New Engl J Med 384(19):1866-1868

135. Organization WH (2021) Methods for the detection and identification of SARS-CoV-2 variants, March 2021. World Health Organization, Regional Office for Europe

136. Organization WH (2021) Genomic sequencing of SARS-CoV-2: a guide to implementation for maximum impact on public health, 8 January 2021

137. Landis J, Moorad R, Pluta LJ, Caro-Vegas C, McNamara RP, Eason AB, et al (2021) Intra-host evolution provides for continuous emergence of SARS-CoV-2 variants. medRxiv

138. Food U, Administration D (2021) Genetic Variants of SARSCoV-2 May Lead to False Negative Results with Molecular Tests for Detection of SARS-CoV-2-Letter to Clinical Laboratory Staff and Health Care Providers. [updated 8 January 2021

139. Vogels CB, Breban M, Alpert T, Petrone ME, Watkins AE, Hodcroft E, et al. (2021) PCR assay to enhance global surveillance for SARS-CoV-2 variants of concern. medRxiv https://doi.org/ 10.1101/2021.01.28.21250486

140. Korukluoglu G, Kolukirik M, Bayrakdar F, Ozgumus GG, Altas AB, Cosgun Y, et al. (2021) 40 minutes RT-qPCR Assay for Screening Spike N501Y and HV69-70del Mutations. bioRxiv https://doi.org/10.1101/2021.01.26.428302

141. Perchetti GA, Zhu H, Mills MG, Shrestha L, Wagner C, Bakhash SM, et al. (2021) Specific allelic discrimination of N501Y and other SARS-CoV-2 mutations by ddPCR detects B 117 lineage in Washington State. medRxiv https://doi.org/10.1101/2021.03. 10.21253321

142. Courjon J-V, Contenti J, Demonchy E, Levraut J, Barbry P, Rios G, et al. (2021) Spread of the SARS-CoV-2 UK-variant in the South East of France: impact on COVID-19 patients age, 
comorbidity profiles and clinical presentation, week 502020 to week 8 2021. medRxiv

143. Wang H, Miller J, Verghese M, Sibai M, Solis D, Mfuh KO, et al. (2021) Multiplex SARS-CoV-2 Genotyping PCR for Population-Level Variant Screening and Epidemiologic Surveillance. medRxiv

144. Banada PP, Green R, Banik S, Chopoorian A, Streck D, Jones R, et al. (2021) A Simple RT-PCR Melting temperature Assay to Rapidly Screen for Widely Circulating SARS-CoV-2 Variants. medRxiv

145. Funk T, Pharris A, Spiteri G, Bundle N, Melidou A, Carr M et al (2021) Characteristics of SARS-CoV-2 variants of concern B.1.1.7, B.1.351 or P.1: data from seven EU/EEA countries, weeks 38/2020 to 10/2021. Euro Surveill 26(16):2100348

146. Bodin K, Rocklov J (2021) Inherent random fluctuations in COVID-19 outbreaks may explain rapid growth of new mutated virus variants. medRxiv

147. Sabino EC, Buss LF, Carvalho MP, Prete CA, Crispim MA, Fraiji NA et al (2021) Resurgence of COVID-19 in Manaus, Brazil, despite high seroprevalence. The Lancet 397(10273):452-455

148. Eguia RT, Crawford KHD, Stevens-Ayers T, Kelnhofer-Millevolte L, Greninger AL, Englund JA et al (2021) A human coronavirus evolves antigenically to escape antibody immunity. PLoS Pathog. 17(4):e1009453

149. Weisblum Y, Schmidt F, Zhang F, DaSilva J, Poston D, Lorenzi JC et al (2020) Escape from neutralizing antibodies by SARSCoV-2 spike protein variants. Elife. 9:e61312

150. Mullard A (2020) How COVID vaccines are being divvied up around the world. Nature

151. Fontanet A, Autran B, Lina B, Kieny MP, Karim SSA, Sridhar D (2021) SARS-CoV-2 variants and ending the COVID-19 pandemic. The Lancet 397(10278):952-954

152. Racaniello V. Is there a limit to how much the coronavirus can mutate? livescience.com, February 11, 2021.

153. Moore JP (2021) Approaches for optimal use of different COVID-19 vaccines: issues of viral variants and vaccine efficacy. JAMA 325(13):1251-1252

154. Meera Chand SH (2020) Gavin Dabrera, Christina Achison, Wendy Barclay, Neil Ferguson, Erik Volz, Nick Loman, Andrew Rambaut, Jeff Barrett Investigation of novel SARS-COV-2 variant Variant of Concern 202012/01. Public Health England, England

155. Andrew Rambaut NL, Oliver Pybus, Wendy Barclay, Jeff Barrett, Alesandro Carabelli, Tom Connor, Tom Peacock, David L Robertson, Erik Volz (2020) Preliminary genomic characterisation of an emergent SARS-CoV-2 lineage in the UK defined by a novel set of spike mutations

156. Cherian S, Potdar V, Jadhav S, Yadav P, Gupta N, Das M et al (2021) SARS-CoV-2 Spike Mutations, L452R, T478K, E484Q and P681R, in the Second Wave of COVID-19 in Maharashtra, India. Microorganisms. 9(7):1542

157. Motozono C, Toyoda M, Zahradnik J, Saito A, Nasser H, Tan TS et al (2021) SARS-CoV-2 spike L452R variant evades cellular immunity and increases infectivity. Cell Host Microbe 29(7):1124-36.e11

158. Chen J, Wang R, Wang M, Wei G-W (2020) Mutations Strengthened SARS-CoV-2 Infectivity. J Mol Biol 432(19):5212-5226

159. Gaebler C, Wang Z, Lorenzi JCC, Muecksch F, Finkin S, Tokuyama M, et al (2020) Evolution of antibody immunity to SARSCoV-2. bioRxiv https://doi.org/10.1101/2020.11.03.367391

160. Nonaka CK, Franco MM, Gräf T, de Lorenzo Barcia CA, de Ávila Mendonça RN, De Sousa KAF et al (2021) Genomic evidence of SARS-CoV-2 reinfection involving E484K spike mutation, Brazil. Emerg Infect Dis 27(5):1522

161. Greaney AJ, Loes AN, Crawford KHD, Starr TN, Malone KD, Chu HY et al (2021) Comprehensive mapping of mutations in the SARS-CoV-2 receptor-binding domain that affect recognition by polyclonal human plasma antibodies. Cell Host Microbe 29(3):463-76.e6

162. Andreano E, Piccini G, Licastro D, Casalino L, Johnson NV, Paciello I, et al. (2020) SARS-CoV-2 escape $<$ em $>$ in vitro $<$ / em $>$ from a highly neutralizing COVID-19 convalescent plasma. bioRxiv. https://doi.org/10.1101/2020.12.28.424451

163. Zhang L, Jackson CB, Mou H, Ojha A, Peng H, Quinlan BD et al (2020) SARS-CoV-2 spike-protein D614G mutation increases virion spike density and infectivity. Nat Commun 11(1):6013

164. Johnson BA, Xie X, Kalveram B, Lokugamage KG, Muruato A, Zou J, et al. (2020) Furin Cleavage Site Is Key to SARSCoV-2 Pathogenesis. bioRxiv https://doi.org/10.1101/2020.08. 26.268854

165. Haynes WA, Kamath K, Lucas C, Shon J, Iwasaki A. (2021) Impact of B.1.1.7 variant mutations on antibody recognition of linear SARS-CoV-2 epitopes. medRxiv. https://doi.org/10.1101/ 2021.01.06.20248960.

Publisher's Note Springer Nature remains neutral with regard to jurisdictional claims in published maps and institutional affiliations. 